\title{
Impacts of High-Resolution Urban Canopy Parameters within the WRF Model on Dynamical and Thermal Fields over Guangzhou, China
}

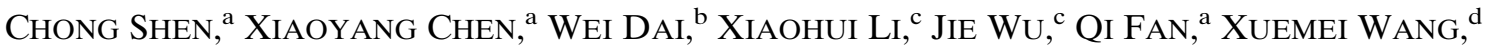 \\ LiYe ZHU, ${ }^{a}$ PAKWAi CHAN, ${ }^{\mathrm{e}}$ JiAn HANG, ${ }^{\text {a }}$ SHAOJIA FAN, ${ }^{a}$ AND WEIBIAO LI ${ }^{\mathrm{a}}$ \\ ${ }^{\text {a }}$ School of Atmospheric Sciences/Guangdong Province Key Laboratory for Climate Change and Natural Disaster Studies, \\ Sun Yat-sen University, Guangzhou, China \\ ${ }^{\mathrm{b}}$ School of Environmental Science and Engineering, Sun Yat-sen University, Guangzhou, China \\ ${ }^{\mathrm{c}}$ Guangzhou Urban Planning Design and Survey Research Institute, Guangzhou, China \\ ${ }^{\mathrm{d}}$ Institute for Environmental and Climate Research, Jinan University, Guangzhou, China \\ ${ }^{\mathrm{e}}$ Hong Kong Observatory, Hong Kong, China
}

(Manuscript received 24 April 2018, in final form 21 March 2019)

\begin{abstract}
On urban scales, the detailed characteristics of land-use information and building properties are vital to improving the meteorological model. The WRF Model with high-spatial-resolution urban fraction (UF) and urban morphology (UM) is used to study the impacts of these urban canopy parameters (UCPs) on dynamical and thermal meteorological fields in two representative seasons in Guangzhou. The results of two seasons are similar and as follows. 1) The impacts of updated UF and UM are obvious on wind speed but minor on temperature and humidity. In the urban environment, the results with updated UF and UM are more consistent with observations compared with the default UCPs, which means the performance of the model has been improved. 2) The dynamical factors associated with wind speed are analyzed. Turbulent kinetic energy (TKE) is significantly affected by UM but little by UF. And both UF and UM are found to influence friction velocity $U^{*}$. The UM and greater UF attained larger $U^{*}$. 3) In addition, the thermal fields are analyzed. The UM and increased UF induce higher surface skin temperature (TSK) and ground heat flux in the daytime, indicating that more heat is transported from the surface to the soil. At night, more heat is transported from the soil to the surface, producing higher TSK. For sensible heat flux (HFX), greater UF induces larger HFX during the daytime. But the effects of UM are complex, which makes HFX decrease during the daytime and increase at night. Finally, larger UF attains lower latent heat in the daytime.
\end{abstract}

\section{Introduction}

With rapid urbanization worldwide, urban extension and the development of metropolitan areas result in the change of land use and land cover and subsequently changes in the physical properties of the land surface such as thermal inertia, albedo, and roughness length. The urban canopy layers of cities are becoming more and more complex because of the various building heights and packing densities. The dynamic characteristics and energy balance of the surface layer, including the exchange of heat, momentum, and water vapor in the boundary layer, are influenced by such changes, which in turn affects local-scale weather and air quality in urban areas (Feddema et al. 2005; Wang et al. 2007, 2009a,b, 2014; Lin et al. 2009; N. Zhang et al. 2010;

Corresponding author: Qi Fan, eesfq@mail.sysu.edu.cn
Miao et al. 2009a,b; Chen et al. 2011a; Mohan and Kandya 2015). To address urban environmental issues and create a better urban microclimate, it is necessary to analyze how urban morphology and the underlying surface in the urban canopy layer influence the urban microclimate (Shui et al. 2016).

In recent years, the urban canopy model (UCM) coupled to mesoscale models has developed rapidly. Chen et al. (2011b) reviewed the development and current status of urban canopy schemes in the Weather Research and Forecasting (WRF) Model, including bulk urban parameterization (BULK) (Liu et al. 2006), single-layer urban canopy model (SLUCM) (Kusaka et al. 2001; Kusaka and Kimura 2004), multilayer urban canopy model (BEP) (Martilli et al. 2002), and a simple building energy model (BEM) (Salamanca and Martilli 2010) linked to BEP. The WRF coupled with UCM (WRF/UCM) has been widely used to study the effects 
of urbanization processes, including the urban heat island effect, urban air quality, and so on. Some researchers have evaluated the simulation of meteorological factors and chemical pollutants by different urban canopy schemes in Athens (Martilli et al. 2003), Texas (Lee et al. 2011), Houston (Salamanca et al. 2011), the Yangtze River delta region (Liao et al. 2014), Chongqing (Y. Wang et al. 2013), and Beijing (Jiang et al. 2016); the studies found that the simulations by the BEP and SLUCM schemes were usually more consistent with the observations than the BULK scheme. Z. Wang et al. (2013) and Yang et al. (2015) proposed a new surface exchange scheme coupling the transport of energy and water in urban canopies, and implemented it into SLUCM in the WRF Model. The results showed that the model performance was improved as compared to the current schemes. Guarino et al. (2014) simulated the urban heat island (UHI) in a medium-size Mediterranean city with the WRF Model including the urban structure with the BEP scheme. It showed overall a better model performance for the city center. Zhou and Chen (2018) applied the WRF with urban canopy model to evaluate the impact of urban morphology changes on the UHI. The high-rise case may lead to lower UHI intensity at the pedestrian level because of the shading effects of highrise buildings. To account for the subgrid-scale heterogeneity of urban areas, Fallmann et al. (2016) used WRF/ Chem coupled with the BEP scheme to study the effect of UHI mitigation measures on urban air quality in Stuttgart, and they found that the urban greening and white roofs could decrease average ozone concentration. de la Paz et al. (2016) used the WRF/Community Multiscale Air Quality (CMAQ) with the BEP scheme to understand the effect on air quality. Compared with the BULK simple scheme, the simulated wind speed was improved significantly over built areas, and BEP also improved the model performance regarding the most relevant pollutants.

In the default WRF/UCM, when the land use in the model grid is identified as "urban," the value of the urban fraction is fixed and there is no spatial difference. Moreover, the urban morphology parameters are specified from a lookup table as a function of the urban land-use type. Shrestha et al. (2011) applied the WRF Model including the gridded anthropogenic heat $(\mathrm{AH})$ emission data of Osaka to assess the contribution of $\mathrm{AH}$ emission toward the formation of UHI. Adachi et al. (2014) introduced high-resolution land surface data, including the spatial distribution of urban fraction and $\mathrm{AH}$ emission, to study the effects on the temperature and UHI with the WRF Model coupled with SLUCM in Tokyo. In China, some researchers also have modified the AH parameterization scheme in the WRF or WRF/Chem model to consider the spatial heterogeneity, and they estimated the spatial distribution of $\mathrm{AH}$ emission over the Pearl River delta (Zhang et al. 2016), Yangtze River delta (Xie et al. 2016), and Hangzhou (Chen et al. 2016) to study the impacts of $\mathrm{AH}$ on the meteorology and air quality. The studies found that $\mathrm{AH}$ emissions can significantly change the urban heat island. He et al. (2019) developed a dataset of three-dimensional urban canopy parameters (UCPs) in the BEP scheme for Beijing and applied it to the WRF to investigate the effects of UCPs on the simulated meteorological variables in clear-sky days. The high-resolution dataset of UCPs improves the model skill in simulating the diurnal variations and spatial distributions of 2-m surface air temperature and 10-m wind speed in the urban canopy, especially for the BEP scheme. Several researchers discussed the necessity of realistically representing urban surfaces and mentioned the development of methods to provide better land-use information; more detailed characteristics of building properties should be addressed to further improve the BEP scheme (Loridan and Grimmond 2012; Loridan et al. 2013; Li et al. 2013; Guarino et al. 2014; de la Paz et al. 2016). The National Urban Database and Access Portal Tool (NUDAPT) (Ching et al. 2009) was only created to provide gridded UCPs datasets for 44 cities in the United States; the spatial coverage of the gridded UCPs is limited. To make up for the lack of this data on urban structures, the World Urban Database and Access Portal Tool (WUDAPT) started mapping urban areas using the local climate zones classification schema (Ching et al. 2014, 2018). However, such detailed UCP data are rarely available, especially in China. In the Noah land surface model (LSM) coupled with BEP, the high-resolution UCPs (urban fraction and urban morphology) are important factors for the simulation of dynamical and thermal fields in urban scale. So far, BEP has seldom been tested for applications involving highresolution runs with the finescale spatial information of urban fraction and urban morphology because of the difficulty for acquiring the urban canopy data.

In this study, we will focus on the BEP scheme coupled to the WRF Model including the influences of detailed landuse information and building properties in Guangzhou. The Guangzhou metropolis is in south-central Guangdong Province, southern China. It has experienced remarkable economic development and urbanization in the past 30 years (Wang et al. 2014). Guangzhou is one of the world's fastest growing megacities (United Nations 2015). Nowadays, the urban land use accounts for about $60 \%$ of the total land cover (Guangzhou Municipal Peoples Government 2016), and it has a very high population density - more than 14 million people-inhabiting this small basin of $7434 \mathrm{~km}^{2}$ through the Baidu encyclopedia of Guangzhou. According to the building information obtained from Guangzhou 
(a)

$106^{\circ} \mathrm{E} \quad 110^{\circ} \mathrm{E} \quad 114^{\circ} \mathrm{E} \quad 118^{\circ} \mathrm{E} \quad 122^{\circ} \mathrm{E}$ (b)

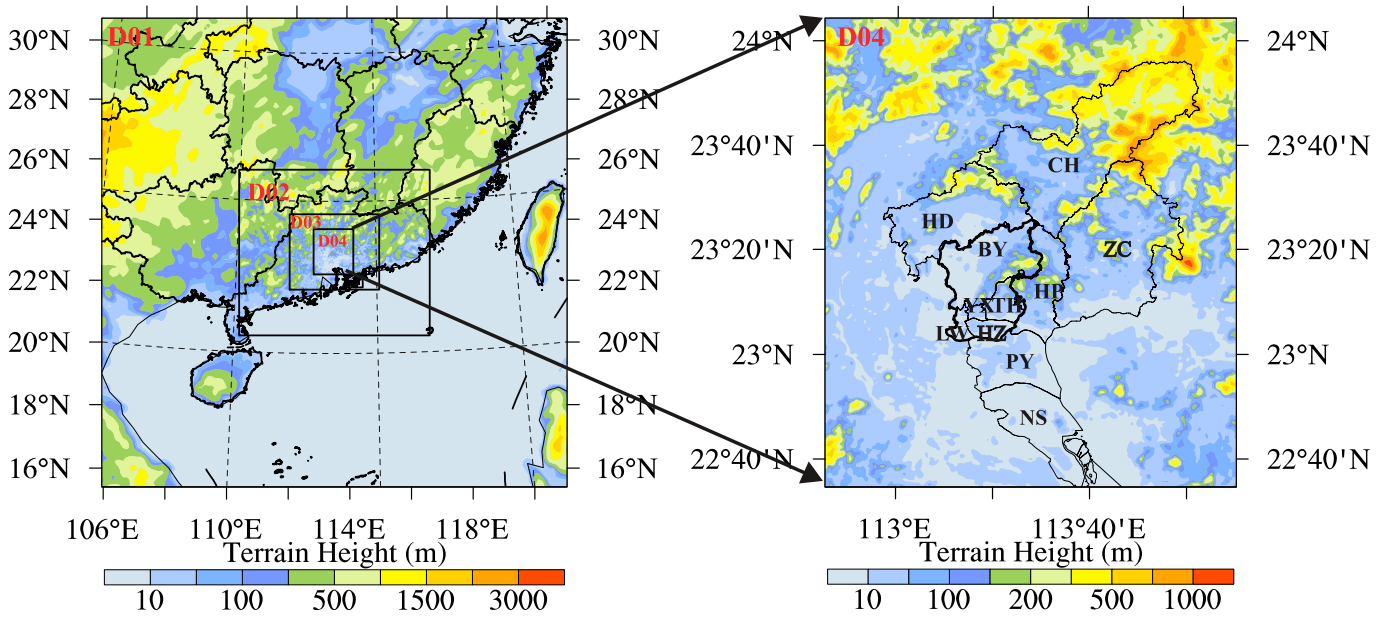

FIG. 1. The (a) simulated domain and (b) locations of districts in Guangzhou; the area with black thicker line is the central urban area (urban) in (b), the same as below.
Urban Planning and Design Survey Research Institute, there are more than 60 buildings with the height over $175 \mathrm{~m}$, and in the central business district, there are seven buildings exceeding 300-m height, and the tallest building is Guangzhou East Tower (about $600 \mathrm{~m}$ ). The characteristics of building structures in Guangzhou are relatively complex and it was chosen as the research region in this study. Detailed and gridded UCPs at high horizontal resolution $(500 \mathrm{~m})$ in Guangzhou, including urban fraction (UF) and urban morphology (UM), were used to study the effects of nonuniform UCPs distribution on dynamical and thermal fields in urban scale with BEP scheme coupled to the WRF Model. It is hoped that this study can improve the simulation performance on the urban scale with the localized high-resolution UCPs, and lay the foundation for further research about the impact of high-resolution UCPs on boundary layer meteorological fields and air quality.

This paper is organized as follows: in section 2, the numerical modeling systems, simulation experiments and the modifications to the BEP scheme are described. Section 3 evaluates the performance of the model and discusses the effects of nonuniform UCPs distribution on dynamical and thermal fields. The paper concludes in section 4 with a summary of the main findings.

\section{Methodology}

The model runs in this study have been carried out using a modified version of WRF, version 3.6.1. The WRF Model is a nonhydrostatic, compressible model with a mass coordinate system. It is a widely used mesoscale meteorological model. The model includes microphysics, cumulus, boundary layer, land surface, and other physical parameterization schemes. A detailed description of WRF was given by Powers et al. (2017).

\section{a. Model configuration}

The WRF Model was configured and four nested domains were constructed with horizontal spatial resolutions of $13.5,4.5,1.5$, and $0.5 \mathrm{~km}$, centering on Guangzhou $\left(23.3^{\circ} \mathrm{N}, 113.5^{\circ} \mathrm{E}\right)$. The gridpoint dimensions were $133 \times 134,163 \times 142,229 \times 193$, and $304 \times 346$, respectively. In most of the previous studies, the finest horizontal spatial grid resolution was $1 \mathrm{~km}$. In this study, the grid resolution in the most inner domain was $0.5 \mathrm{~km}$. This will be beneficial for capturing more nonuniform urban structure characteristics with higher resolution in the model. But it should be mentioned that as the resolution in numerical weather prediction models increases, turbulent motion can be partially resolved by gridscale dynamics. However, a substantial part of turbulent motion still needs to be parameterized, which may result in the so-called terra incognita problem, especially for the planetary boundary layer (PBL) parameterization scheme in the model.

Figure 1 shows the locations of the simulated nested domains and the innermost domain (D04), comprising the whole city of Guangzhou. It includes 11 districts: Haizhu (HZ), Yuexiu (YX), Liwan (LW), Tianhe (TH), Baiyun (BY), Huadu (HD), Panyu (PY), Nansha (NS), Huangpu (HP), Conghua ( $\mathrm{CH})$, and Zengcheng (ZC). Tables 1 and 2 show the statistics of UF and UM in different districts of Guangzhou. It should be noted that $\mathrm{ZC}$ and $\mathrm{CH}$ belong to the mountain area, where the urban development is relatively small, and so this study 
TABLE 1. Statistics about the UF in different districts; please refer to section 2c(i) for detailed descriptions. The percent of the urban represents the proportion of urban land-use type area to the total area of each district. The mean UF represents the average urban fraction of each district. The max UF represents the maximum urban fraction of each district. The default value is specified from a lookup table in the Base and Case 2 experiment setting.

\begin{tabular}{|c|c|c|c|c|c|c|c|c|c|c|c|}
\hline \multirow[b]{2}{*}{ District } & \multicolumn{6}{|c|}{ Urban } & \multicolumn{5}{|c|}{ Suburbs } \\
\hline & YX & $\mathrm{HZ}$ & TH & LW & BY & Mean & HP & HD & PY & NS & Mean \\
\hline Percent of the urban & $100.00 \%$ & $46.85 \%$ & $57.22 \%$ & $51.87 \%$ & $24.41 \%$ & $56.07 \%$ & $14.81 \%$ & $5.90 \%$ & $18.82 \%$ & $7.47 \%$ & $11.75 \%$ \\
\hline Percent $(\mathrm{UF}>0.6)$ & $27.5 \%$ & $54.8 \%$ & $30.3 \%$ & $50.4 \%$ & $39.9 \%$ & $40.6 \%$ & $20.3 \%$ & $29.0 \%$ & $32.9 \%$ & $9.5 \%$ & $22.9 \%$ \\
\hline Percent (UF < 0.6) & $72.5 \%$ & $45.2 \%$ & $69.7 \%$ & $49.6 \%$ & $60.1 \%$ & $59.4 \%$ & $79.7 \%$ & $71.0 \%$ & $67.2 \%$ & $90.5 \%$ & $77.1 \%$ \\
\hline Mean UF & 0.47 & 0.58 & 0.45 & 0.57 & 0.45 & 0.50 & 0.35 & 0.39 & 0.46 & 0.23 & 0.36 \\
\hline Max UF & 0.94 & 0.97 & 0.95 & 0.93 & 0.99 & 0.96 & 0.90 & 0.94 & 1.00 & 1.00 & 0.96 \\
\hline
\end{tabular}

is mainly concerned with the other nine districts. In Table 1, we calculated the proportion of the urban landuse type area to the total area of each district (percent of the urban), the average urban fraction of each district (mean UF) and so on. Based on the statistics data in each district, a district with the percent of the urban larger than $20 \%$ and the mean UF larger than or equal to 0.45 is defined as "urban." Thus, HZ, YX, LW, TH, and $\mathrm{BY}$ are classified as urban, see the area with black thicker line in Fig. 1b, and the other four districts (HP, PY, HD, and NS) are classified as "suburbs."

A total of 30 eta levels with a pressure of $50 \mathrm{hPa}$ at the top level were used, and the lowest level was set at about $13 \mathrm{~m}$ above the ground surface. The initial and boundary conditions at the outermost domain were interpolated from $1^{\circ}$ resolution final analysis data (FNL). The simulation periods were from 31 October to 10 November 2016 and from 31 March to 10 April 2017, which were clear days, as the representative periods of the dry and wet seasons in Guangzhou (Jian 1994). Considering the spinup time, only the results from 1 to 8 November 2016 and from 1 to 8 April 2017 were analyzed. For the landuse categories, the default data that originated from the U.S. Geological Survey (USGS) or Moderate Resolution Imaging Spectroradiometer (MODIS) was replaced with a Global Land Cover 2009 (GLC2009) land-use database. In Pearl River delta (PRD) region, the GLC2009 was demonstrated to be more consistent with the current situation (Chang et al. 2014). Regarding the physical options, the New Goddard shortwave radiation scheme, the Rapid Radiative Transfer Model (RRTM) longwave radiation scheme, the Lin microphysics scheme, and the BouLac planetary boundary layer scheme were selected. The Kain-Fritsch cumulus scheme was employed in domains 1 and 2. The simulations were run with the Noah LSM (Chen and Dudhia 2001) coupled with BEP (Martilli et al. 2002) for the land surface processes parameterization. For this study, the distributions of updated UCPs of Guangzhou were also set in the model, which will be presented in section $2 \mathrm{c}$.

\section{b. Description of LSM coupled with BEP in WRF}

Among the options for the LSMs in WRF, the Noah LSM has been widely used (Chen et al. 2011b). The main function of the Noah LSM is to provide the bottom boundary variables for WRF, following Eq. (1). Here, $A$ are the variables from the surface to the lowest layer of the grid in WRF, such as sensible heat flux, latent heat flux, surface temperature, upward longwave radiation, albedo, and friction velocity; $A_{\mathrm{veg}}$ are the variables from Noah LSM for natural surfaces, and $A_{\text {urb }}$ are the variables for artificial surfaces; VF are the fractional

TABLE 2. Statistics about the UM in different districts; please refer to section 2c(ii) for detailed descriptions. The mean BW, SW, BH, and SBH represent the average values of each district. The max BH represents the maximum building height of each district. The default values are specified from a lookup table in Base and Case 1 experiment setting.

\begin{tabular}{|c|c|c|c|c|c|c|c|c|c|c|c|}
\hline \multirow[b]{2}{*}{ District } & \multicolumn{6}{|c|}{ Urban } & \multicolumn{5}{|c|}{ Suburbs } \\
\hline & $\mathrm{YX}$ & $\mathrm{HZ}$ & $\mathrm{TH}$ & $\mathrm{LW}$ & $\mathrm{BY}$ & Mean & HP & $\mathrm{HD}$ & PY & NS & Mean \\
\hline Percent $(\mathrm{BW}<20 \mathrm{~m})$ & $100.0 \%$ & $99.5 \%$ & $100.0 \%$ & $99.3 \%$ & $100.0 \%$ & $99.7 \%$ & $99.0 \%$ & $100.0 \%$ & $99.5 \%$ & $100.0 \%$ & $99.6 \%$ \\
\hline Mean BW (m) & 6.15 & 6.08 & 5.90 & 5.97 & 4.76 & 5.77 & 4.94 & 4.39 & 4.97 & 2.89 & 4.30 \\
\hline Percent $(\mathrm{SW}<20 \mathrm{~m})$ & $94.6 \%$ & $90.9 \%$ & $85.2 \%$ & $87.1 \%$ & $83.1 \%$ & $88.2 \%$ & $79.3 \%$ & $86.5 \%$ & $86.8 \%$ & $85.5 \%$ & $84.6 \%$ \\
\hline Mean SW (m) & 6.34 & 9.93 & 11.49 & 13.72 & 14.97 & 11.29 & 14.49 & 11.71 & 10.94 & 13.86 & 12.75 \\
\hline Percent $(\mathrm{BH}>24 \mathrm{~m})$ & $25.5 \%$ & $19.4 \%$ & $16.3 \%$ & $2.9 \%$ & $2.3 \%$ & $13.3 \%$ & $3.0 \%$ & $0.8 \%$ & $1.9 \%$ & $1.8 \%$ & $1.9 \%$ \\
\hline Mean BH (m) & 19.34 & 16.86 & 15.52 & 12.15 & 8.75 & 14.52 & 7.36 & 7.76 & 8.24 & 4.88 & 7.06 \\
\hline $\operatorname{Max} \mathrm{BH}(\mathrm{m})$ & 55.11 & 52.54 & 72.59 & 31.12 & 62.13 & 54.70 & 41.76 & 29.35 & 30.45 & 31.13 & 33.17 \\
\hline Percent $(\mathrm{SBH}>4.6 \mathrm{~m})$ & $91.3 \%$ & $91.9 \%$ & $79.5 \%$ & $68.3 \%$ & $55.2 \%$ & $77.3 \%$ & $37.0 \%$ & $46.1 \%$ & $40.8 \%$ & $19.0 \%$ & $35.7 \%$ \\
\hline Mean SBH (m) & 11.87 & 11.64 & 11.14 & 7.78 & 5.53 & 9.59 & 4.68 & 5.24 & 4.98 & 3.04 & 4.48 \\
\hline
\end{tabular}


(a)

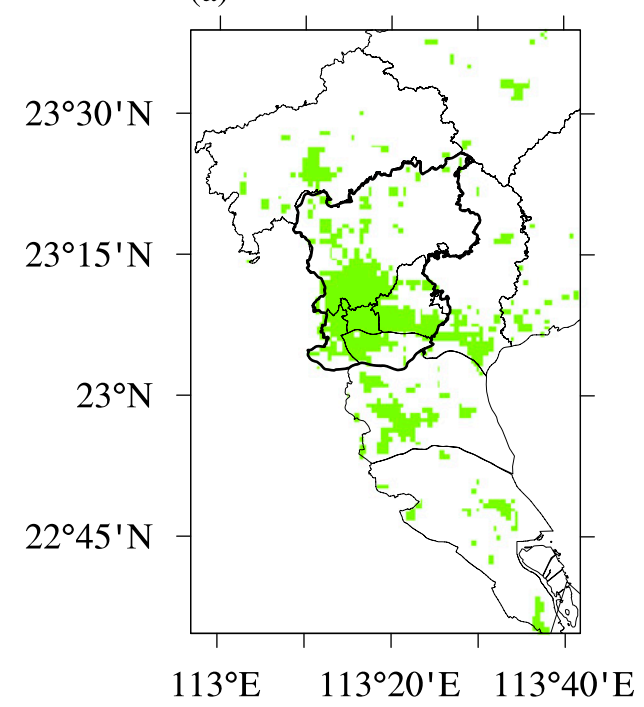

(b)

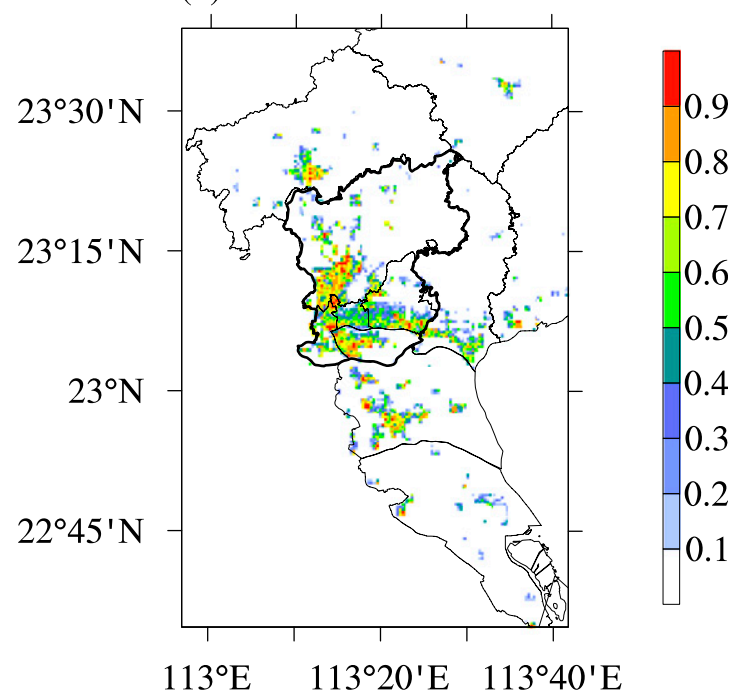

FIG. 2. Urban land use in Guangzhou region: (a) urban fraction fixed at 0.6 in the BEP scheme (Base experiment); (b) high-resolution urban fraction in Guangzhou (Case 1 and Case 3 experiments).

coverages of natural surfaces; and UF are the fractional coverages of artificial surfaces, which are also regarded as urban fraction. The sum of VF and UF is one:

$$
A=\mathrm{VF} \times A_{\mathrm{veg}}+\mathrm{UF} \times A_{\mathrm{urb}} .
$$

The term $A_{\text {urb }}$ is calculated by urban canopy model, which is chosen as the BEP scheme in this study. BEP coupled to the Noah LSM, developed for the building effect parameterization, represents the most sophisticated urban modeling in WRF (Martilli et al. 2002). BEP can consider the impact of horizontal and vertical surfaces in momentum, turbulence, and heat equations. The radiation around walls and roads shows the shadowing, reflections, and captures of shortwave and longwave radiation in street canyons. BEP can simulate some urban atmospheric environmental characteristics, such as the urban wind environment and so on, according to the UM (Chen et al. 2011b). In the Noah LSM coupled with BEP, UF and UM are two key factors for the simulation of dynamical and thermal fields at the urban scale.

\section{c. Improvement of the distribution of UCPS}

\section{1) URBAN FRACTION}

In the Noah LSM coupled with BEP, UF is one of the most important parameters for giving the urban percentage that represents the proportion of impervious surfaces in the WRF subgrid. The proportion of variables (fluxes, surface temperatures, etc.) in artificial and natural surfaces, such as VF and UF in Eq. (1), are given by this parameter. In the default BEP scheme, UF in the urban parameters table (URBPARM.TBL) is fixed at 0.95 . However, in reality, the calculated urban average coverage rate of Guangzhou is about 0.6 according to the Plan of Ecological Civilization Construction in Guangzhou, which is much lower than the default value in BEP scheme. Thus, we replaced the default 0.95 with 0.6 in the Base experiment setting. This value (0.6) was given to all the urban and suburbs land-use grids, as illustrated in Fig. 2a. However, UF distribution is not uniform in the real world, thus the fixed UF value of 0.6 does not well represent the regional distribution differences of UF. Therefore, a finer scale of the UF dataset has been achieved and applied to other experimental cases in this study.

To characterize the UF more precisely in the BEP scheme, a detailed 2D spatial distribution of UF with 500-m resolution (Fig. 2b) was established according to the 30-m high-resolution land-use information obtained from Landsat in 2010 (Zhang and Roy 2017). From the statistics in Table 1 and Fig. 2, it is found that the percentages of area with UF less than 0.6 are $45.2 \%$ and $49.6 \%$ in $\mathrm{HZ}$ and $\mathrm{LW}$, respectively. In other districts, the areas of UF less than 0.6 are larger than $60 \%$, among which the proportion of urban areas with UF under 0.6 is $90.5 \%$ in NS district. Moreover, the mean UFs are 0.5 and 0.36 in the urban areas and suburbs, respectively, which are lower than the default value of 0.6 in the Base experiment. The high-resolution data can provide more heterogeneity and accurate distribution characteristics of UF in Guangzhou. The effects of the uniform and nonuniform UF distribution on dynamical and thermal fields at the urban scale will be discussed in later sections. 


\section{2) URBAN MORPHOLOGY}

In addition to UF, UM is also an important urban canopy parameter at the urban scale. Four main UM parameters (building width, street width, street direction, and distribution of building heights) are considered in the BEP scheme. Usually, these four UM parameters are fixed in the urban parameters table: the building and street widths are both $20 \mathrm{~m}$, and the street directions are divided into $0^{\circ}$ and $90^{\circ}$. The distribution of building heights includes two parts, building heights and their corresponding proportions, which are $10 \%, 25 \%, 40 \%$, and $25 \%$ corresponding to building heights of $15,20,25$, and $30 \mathrm{~m}$, respectively.

At this point, a more detailed UM data with high horizontal resolution $(500 \mathrm{~m})$ was established according to the building information obtained from the Guangzhou Urban Planning and Design Survey Research Institute. These data, as used in the WRF preprocessing system (WPS), are bundled together into a single array called URB_PARAM that contains all the UM parameters (Glotfelty et al. 2013). The building width (BW) is a function of three urban morphology parameters from the URB_PARAM, including plan area fraction (PAF), the building surface to plan area ratio (BPR), and the area-weighted mean building height $(\mathrm{BH})$. In addition to these three parameters, UF is also included in the calculation of the street width (SW).

The PAF is defined as the ratio of the plan area of buildings to the total surface area of the study region. The BPR is defined as the sum of the building surface area divided by the total plan area. The PAF and BPR were calculated as follows:

$$
\begin{aligned}
& \mathrm{PAF}=A_{p} / A_{T}, \quad \text { and } \\
& \mathrm{BPR}=\left(A_{R}+A_{W}\right) / A_{T},
\end{aligned}
$$

where $A_{p}$ is the plan area of buildings at ground level, $A_{R}$ is the plan area of rooftops, $A_{W}$ is the total area of nonhorizontal roughness element surfaces (e.g., walls), and $A_{T}$ is the total plan area of the study region (Burian et al. 2005).

Based on the default calculation formulas in the multilayer urban canopy scheme, the calculations of the BW and SW are as follows:

$$
\begin{aligned}
& \mathrm{BW}=2 \times \mathrm{BH} \times \mathrm{PAF} /(\mathrm{BPR}-\mathrm{PAF}), \quad \text { and } \\
& \mathrm{SW}=2 \times \mathrm{BH} \times \mathrm{PAF} \times(\mathrm{UF} / \mathrm{PAF}-1) /(\mathrm{BPR}-\mathrm{PAF}) .
\end{aligned}
$$

The calculated building width and street width are shown in Figs. 3a and 3b. From the statistics in Table 2, it is found that the mean BW and SW are less than $20 \mathrm{~m}$ (default) in each district, and the area percent of the BW and SW under $20 \mathrm{~m}$ are above $99 \%$ and $79 \%$, respectively, which indicate the narrower street canyons and higher density buildings in urban grids. The street directions are divided into $0^{\circ}, 45^{\circ}, 90^{\circ}$, and $135^{\circ}$. And the distributions of building heights that contain 15 intervals are vertically resolved with $5-\mathrm{m}$ intervals spanning 0 $75 \mathrm{~m}$ (figures omitted). The $\mathrm{BH}$ and standard deviation of building height (SBH) in urban grids are calculated (He et al. 2019), as shown in Figs. 3c and 3d. In YX, HZ and $\mathrm{TH}$ districts, the area percent of $\mathrm{BH}$ greater than $24 \mathrm{~m}$ (default) is larger than $16 \%$, and the maximum $\mathrm{BH}$ is $72.59 \mathrm{~m}$ in $\mathrm{TH}$ district. In other districts, the BHs in most areas are less than $24 \mathrm{~m}$. In addition to NS district, the mean SBH is higher than $4.6 \mathrm{~m}$ (default), and the mean area percents of the SBH larger than $4.6 \mathrm{~m}$ are $77.3 \%$ in the urban areas and $35.7 \%$ in the suburbs, which indicate more obvious urban morphological differences occur in the urban areas.

\section{d. Experimental design}

Sensitivity experiments were designed to study the impacts of the high-resolution UCPs (UF and UM) on the dynamical and thermal fields. Four sensitivity scenarios were set (Table 3). The UF and UM involved in the Base experiment followed the homogeneous settings in the model. In the Case 1 and Case 2 experiments, the homogeneous UF and UM were updated separated. In the Case 3 experiment, UF and UM were both updated by the high-resolution data. Accordingly, the effects of UF (Case 1 - Base), UM (Case 2 - Base), and combined UF and UM (Case 3 - Base) can be analyzed.

\section{Results}

\section{a. Model evaluation}

In this section, the hourly simulation results with the high-resolution UCPs in the model are compared with the hourly observations by calculating the statistical variables, including deviation (bias), the mean absolute error (MAE), square root error (RMSE), and correlation coefficient $R$, and are defined as

$$
\begin{aligned}
\text { bias } & =\frac{1}{N} \sum_{i=1}^{N}\left(S_{i}-O_{i}\right), \\
\text { MAE } & =\frac{1}{N} \sum_{i=1}^{N}\left|S_{i}-O_{i}\right|, \\
\text { RMSE } & =\sqrt{\frac{1}{N} \sum_{i=1}^{N}\left(S_{i}-O_{i}\right)^{2}}, \text { and }
\end{aligned}
$$


(a)

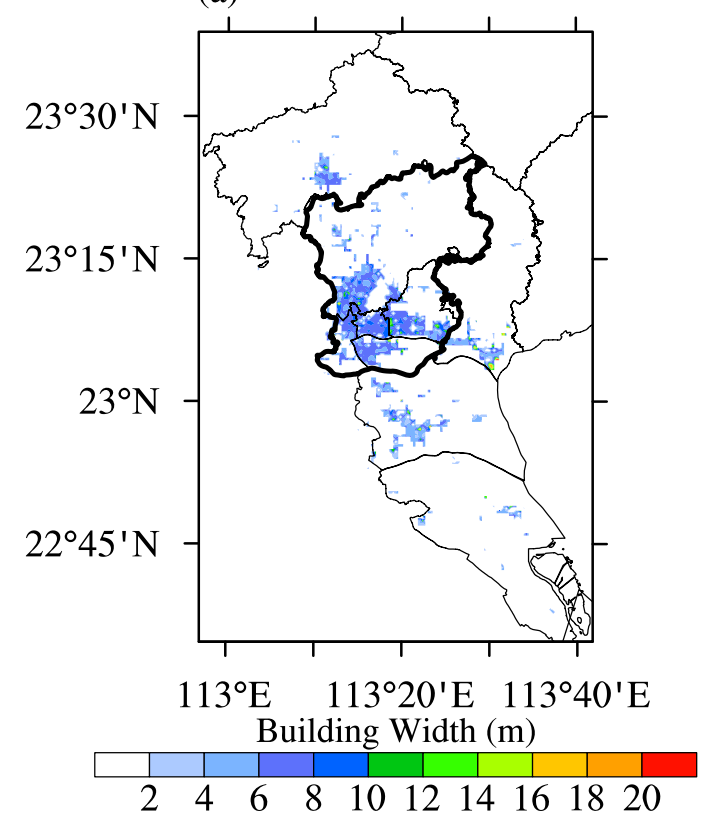

(c)

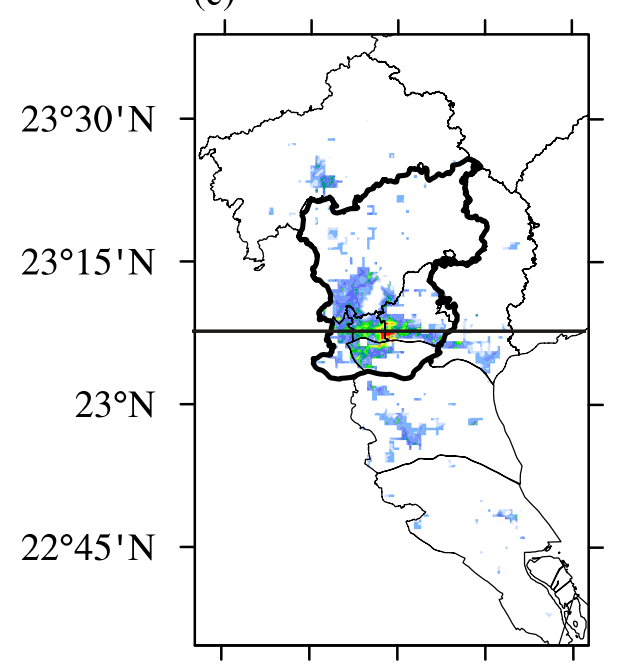

$113^{\circ} \mathrm{E} \quad 113^{\circ} 20^{\prime} \mathrm{E} \quad 113^{\circ} 40^{\prime} \mathrm{E}$

Area Weighted Mean Building Height (m)

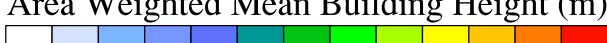

(b)

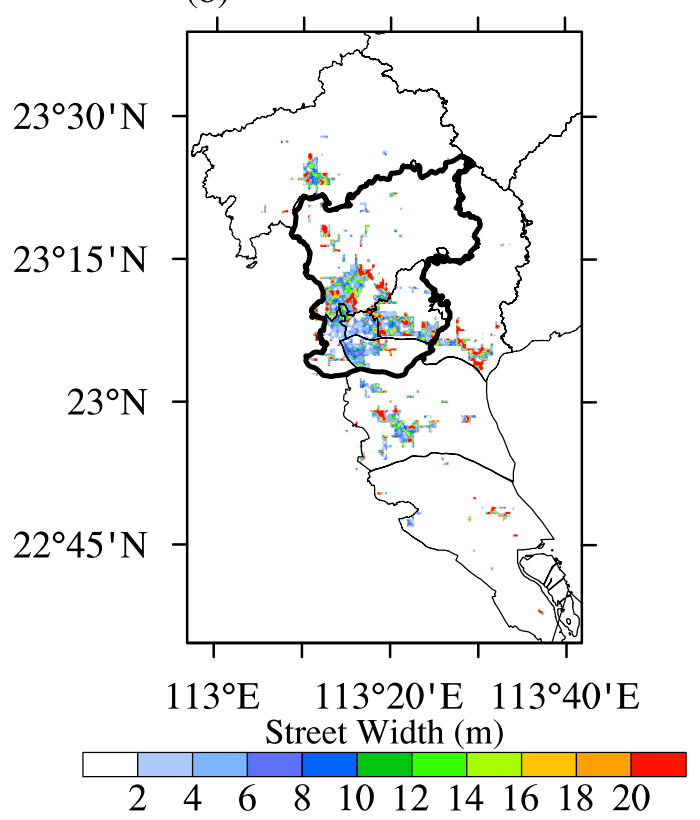

(d)

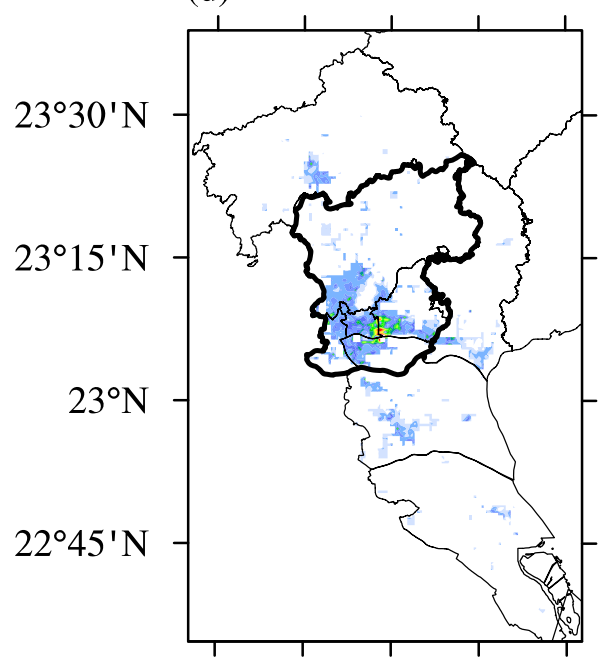

$113^{\circ} \mathrm{E} \quad 113^{\circ} 20^{\prime} \mathrm{E} \quad 113^{\circ} 40^{\prime} \mathrm{E}$

Standard Deviation of Building Height (m)

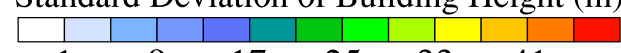

FIG. 3. High-resolution urban morphology in Guangzhou region: (a) the building width, (b) the street width, (c) area-weighted mean building height, and (d) the standard deviation of building height.

$$
R=\frac{\sum_{i=1}^{N}\left(S_{i}-S^{\prime}\right)\left(O_{i}-O^{\prime}\right)}{\sqrt{\sum_{i=1}^{N}\left(S_{i}-S^{\prime}\right)^{2}} \sqrt{\sum_{i=1}^{N}\left(O_{i}-O^{\prime}\right)^{2}}}
$$

where $N$ is 192 times (8 days), $S_{i}$ is the simulation and $O_{i}$ is the observation, and $S^{\prime}$ and $O^{\prime}$ are the average values of simulated data and observed data at each weather station, respectively. The evaluated meteorological factors include 2-m temperature (T2), 2-m relative humidity (RH) and $10-\mathrm{m}$ wind speed (WS). The observations at 167 automatic weather stations in November 2016 and 41 automatic weather stations in April 2017 have been used from the Guangzhou Meteorological Service. 
TABLE 3. Details of the sensitivity scenarios. Default: urban canopy parameters are specified from a lookup table; UF: the fixed value is 0.6 ; UM: the building and street width are both $20 \mathrm{~m}$; building heights and their corresponding proportions are $10 \%, 25 \%, 40 \%$, and $25 \%$ corresponding to building heights of $15,20,25$, and $30 \mathrm{~m}$, respectively. Updated: the detailed $2 \mathrm{D}$ spatial distribution of UF and UM data with high horizontal resolution are used in the WRF preprocessing system (WPS); UF: see Fig. 2 b for details; UM: the building and street widths are shown in Figs. $3 \mathrm{a}$ and $3 \mathrm{~b}$, the distributions of building heights that contain 15 intervals are vertically resolved with $5-\mathrm{m}$ intervals spanning $0-75 \mathrm{~m}$.

\begin{tabular}{lcccc}
\hline \hline & Base & Case 1 & Case 2 & Case 3 \\
\hline Urban fraction (UF) & Default & Updated & Default & Updated \\
Urban morphology (UM) & Default & Default & Updated & Updated
\end{tabular}

Table 4 shows the 8 -day averaged statistical variables for model evaluation in the urban areas and suburbs during April and November, and the statistical variables (bias, MAE, RMSE, and $R$ ) are averages of weather stations in the urban areas and suburbs, respectively. The $R$ values between the simulated and observed T2, $\mathrm{RH}$, and WS do not change much among different experiments and the values are all greater than 0.7 except for the wind speed in April, which indicate that the simulated results are generally in good agreement with the observations in both urban areas and suburbs. In urban areas, the deviations of observed and simulated $\mathrm{T} 2$ are $0.74^{\circ} \mathrm{C}$ (Base), $0.65^{\circ} \mathrm{C}$ (Case 1$), 0.74^{\circ} \mathrm{C}$ (Case 2), and $0.65^{\circ} \mathrm{C}$ (Case 3 ) in April and $0.12^{\circ} \mathrm{C}$ (Base), $0.04^{\circ} \mathrm{C}$ (Case 1 ), $0.06^{\circ} \mathrm{C}$ (Case 2), and $-0.01^{\circ} \mathrm{C}$ (Case 3) in November, respectively. It can be seen that the impacts of high-resolution UCPs on T2 is small. The same finding has been found in $\mathrm{RH}$ results: the deviations of simulated and observed RH are $-3.13 \%$ (Base), $-2.52 \%$ (Case 1 ), $-2.93 \%$ (Case 2), and $-2.37 \%$ (Case 3) in April and 2.24\% (Base), $2.77 \%$ (Case 1), 2.74\% (Case 2), and 3.22\% (Case 3 ) in November. Compared with $\mathrm{T} 2$ and $\mathrm{RH}$, the differences of simulated WS among the experiments are significant. In Case 3, with the highresolution UCPs updated in the model, the bias, MAE, and RMSE of WS are all decreased in the urban areas. The average deviations of the simulation and observation results are reduced from $2.30 \mathrm{~m} \mathrm{~s}^{-1}$ (Base) to $1.66 \mathrm{~m} \mathrm{~s}^{-1}$ (Case 3) in April and from $1.30 \mathrm{~m} \mathrm{~s}^{-1}$ (Base) to $0.83 \mathrm{~m} \mathrm{~s}^{-1}$ (Case 3) in November. When only highresolution UM data are considered, the improvement of WS is more obvious, and the deviations are reduced from $2.30 \mathrm{~m} \mathrm{~s}^{-1}$ (Base) to $1.61 \mathrm{~m} \mathrm{~s}^{-1}$ (Case 2) in April and from $1.30 \mathrm{~m} \mathrm{~s}^{-1}$ (Base) to $0.77 \mathrm{~m} \mathrm{~s}^{-1}$ (Case 2) in November. Combined with the time series of averaged $10-\mathrm{m}$ wind speed for the different scenarios in the urban areas and suburbs (Fig. 4), it also can be found that UF

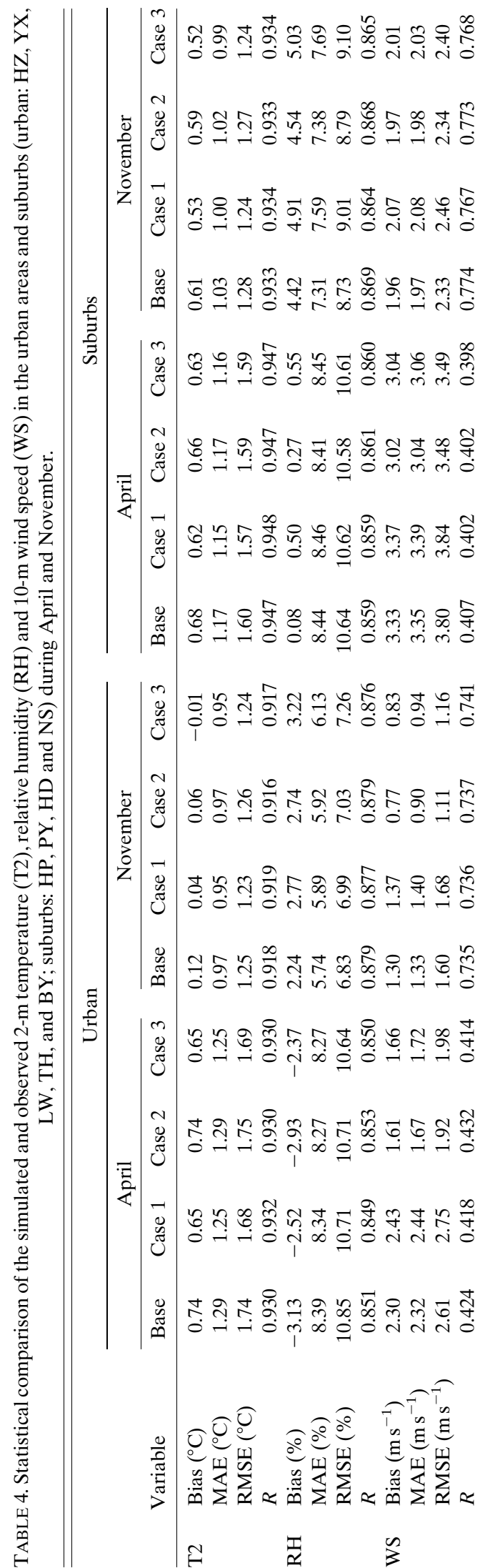


(a)

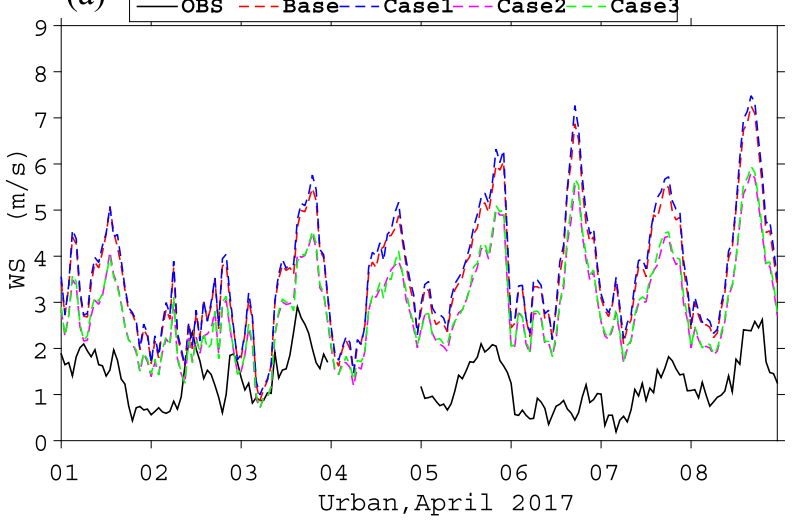

(c)

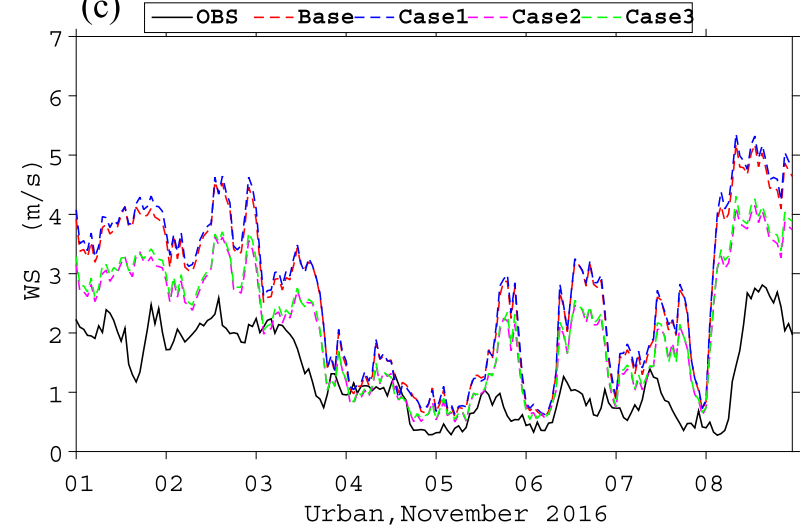

(b)

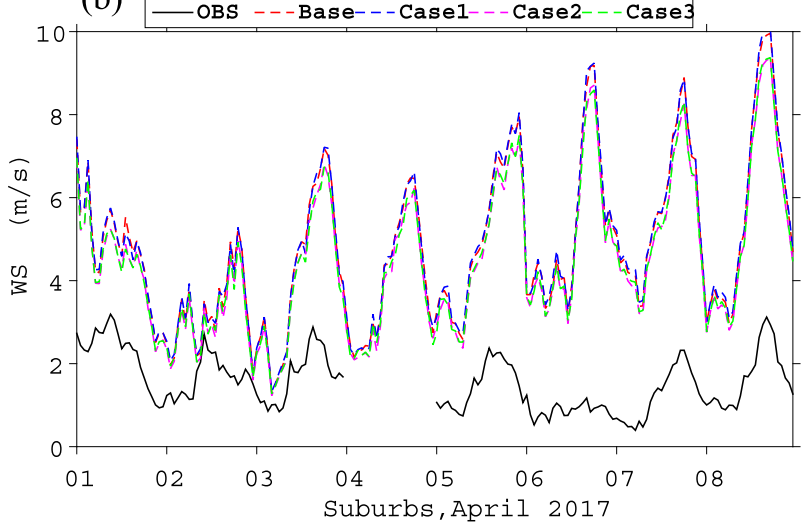

(d)

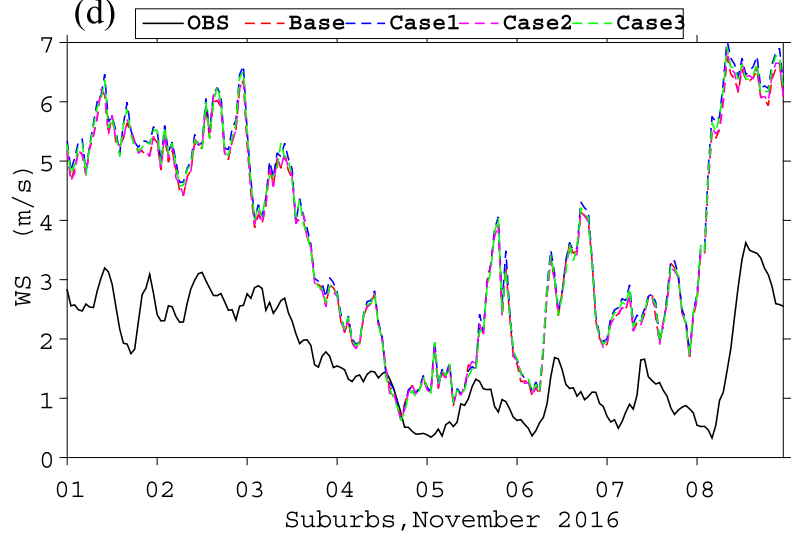

FIG. 4. Time series of the averaged 10-m wind speed (WS) for the different scenarios compared with the observed data obtained from automatic weather stations in the urban areas and suburbs during April and November.

and UM have little impact on T2 and RH (figure omitted) and can significantly improve the simulation results of WS in the central urban area.

Figure 5 displays the spatial distributions of the 8-day averaged WS deviation for the different scenarios compared with the observed data during April and November. Compared with the Base experiment, the influence of updated UF data (Case 1) on the WS simulation performance is very small in each district. While considering the updated UM data (Case 2) or both the updated UF and UM data (Case 3), the deviation of observed and simulated WS are significantly reduced at the observation stations in the built-up area (LW, HZ, $\mathrm{TH}$, and YX districts), and the simulation performance of WS is improved in April and November. However, the deviations of observed and simulated WS have no significant changes at the observation stations in NS, PY, $\mathrm{HD}$, and HP districts. From the distributions of the averaged WS deviation in the Base experiment, the simulated WS are mostly overestimated in Guangzhou, especially in April. Under the effect of distributed urban morphology (Case 2), the simulated WSs are significantly reduced in the $\mathrm{LW}, \mathrm{HZ}, \mathrm{TH}$, and YX districts, while still relatively higher in NS and HD districts. It shows that the densely built-up areas of Guangzhou produced the lower WS, which is consistent with the conclusion of Varquez et al. (2015). Therefore, the spatial distribution characteristics of meteorological elements in the urban areas may be affected by the urban underlying surface and building morphological structure. So the next part will focus on the influences of highresolution UCPs (UF and UM) on the dynamical and thermal fields.

\section{b. Effects of high-resolution UCPs on dynamical fields}

This section focuses on the effects of the highresolution UF (Case 1 - Base) and UM (Case 2 - Base) on the dynamic related variables, including friction velocity $U^{*}$ (Fig. 6), wind speed (horizontal and vertical distribution) (Figs. 7 and 9 ) and turbulent kinetic energy (TKE) (Fig. 8). The $U^{*}$ can represent surface characteristics, which is mainly related with the roughness length. The $U^{*}$ is calculated in the artificial and natural underlying surface by UF and affects the calculation of radial and zonal wind. The terms in the TKE equation 

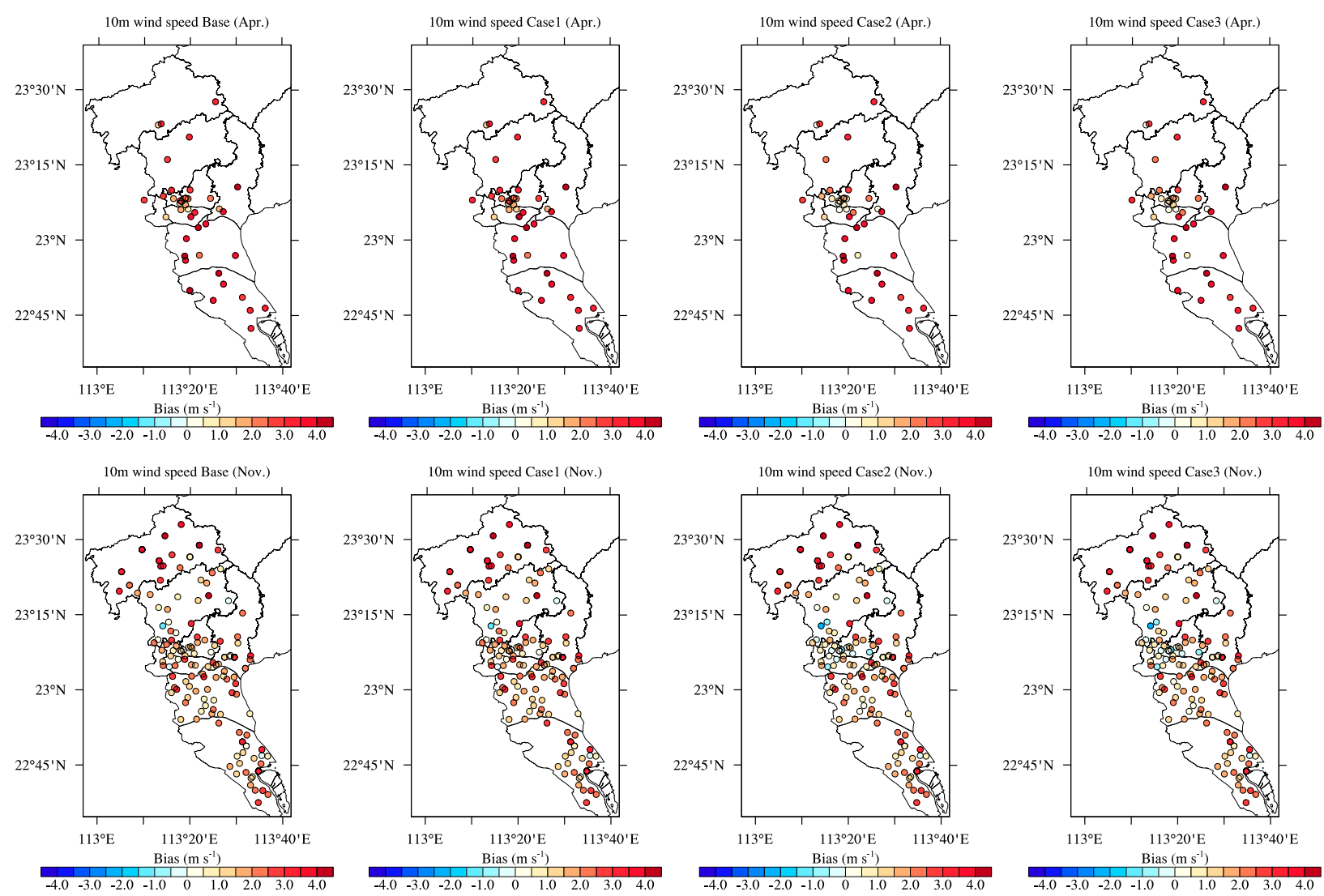

FIG. 5. The deviation (bias) of 8-day averaged 10-m wind speed for the different scenarios compared with the observed data during April and November.

can be divided into four parts: shear production, buoyant production, viscous dissipation, and the effects of vertical (walls) and horizontal (streets and roofs) surfaces on TKE. Among these four terms, only the last term, which was calculated in the BEP scheme, considers the effect of UF.

Here, the separated influence of UF and UM on $U^{*}$ is analyzed (Fig. 6). The difference of simulated $U^{*}$ between Case 1 and Base represents the impacts of the highresolution UF on $U^{*}$, and the difference between Case 2 and Base represents the impacts of UM. The increase of UF causes $U^{*}$ increase and vice versa in April and November. According to Eq. (1), the calculation of $U^{*}$ is divided into two parts: artificial surface and natural surface in the subgrid. In general, the roughness length of artificial underlying surface (about $1 \mathrm{~m}$ ) is significantly greater than that of natural surface (about $0.01-0.2 \mathrm{~m}$ ) (Stull 1990). When UF increases, the contribution of $U^{*}$ growth in artificial surface is larger than that of $U^{*}$ reduction in natural surface, so that the total $U^{*}$ increases in the grids. In the urban areas, the inclusion of UM produces larger $U^{*}$ (April: $0.025 \mathrm{~m} \mathrm{~s}^{-1}$; November: $0.017 \mathrm{~m} \mathrm{~s}^{-1}$ ). Among the urban districts, the impacts of
$\mathrm{UM}$ on $U^{*}$ are most significant in $\mathrm{YX}, \mathrm{HZ}$, and $\mathrm{TH}$ districts, increased by $0.026,0.052,0.030 \mathrm{~m} \mathrm{~s}^{-1}$ in April and $0.020,0.038,0.024 \mathrm{~m} \mathrm{~s}^{-1}$ in November, respectively. The reason is that the differences of urban morphology are more obvious in the above three districts. It enhances the surface roughness and leading to the increase of $U^{*}$.

The influences of UF and UM on wind speed are opposite to those of $U^{*}$ (Fig. 7). In the urban areas, the decrease of UF causes an increase of wind speed by $0.165 \mathrm{~m} \mathrm{~s}^{-1}$ and $0.117 \mathrm{~m} \mathrm{~s}^{-1}$ in April and November. UF also makes the wind speed significantly increased by $0.373 \mathrm{~m} \mathrm{~s}^{-1}$ and $0.252 \mathrm{~m} \mathrm{~s}^{-1}$ in the suburbs during April and November. Compared with the default UF (0.6), UF in the suburbs (0.36) changes more than that in the urban areas $(0.5)$, so the wind speed changes more obviously in the suburbs. On the other side, the inclusion of UM makes the wind speed significantly reduced in the urban areas (April: $0.777 \mathrm{~m} \mathrm{~s}^{-1}$; November: $0.553 \mathrm{~m} \mathrm{~s}^{-1}$ ) and slightly reduced in the suburbs (April: $0.253 \mathrm{~m} \mathrm{~s}^{-1}$; November: $0.182 \mathrm{~m} \mathrm{~s}^{-1}$ ). The reason is that the highresolution UM increases the difference of building heights, resulting in the increase of surface roughness, and the buildings have a significant drag effect on the wind 
(a) UF(Apr.)

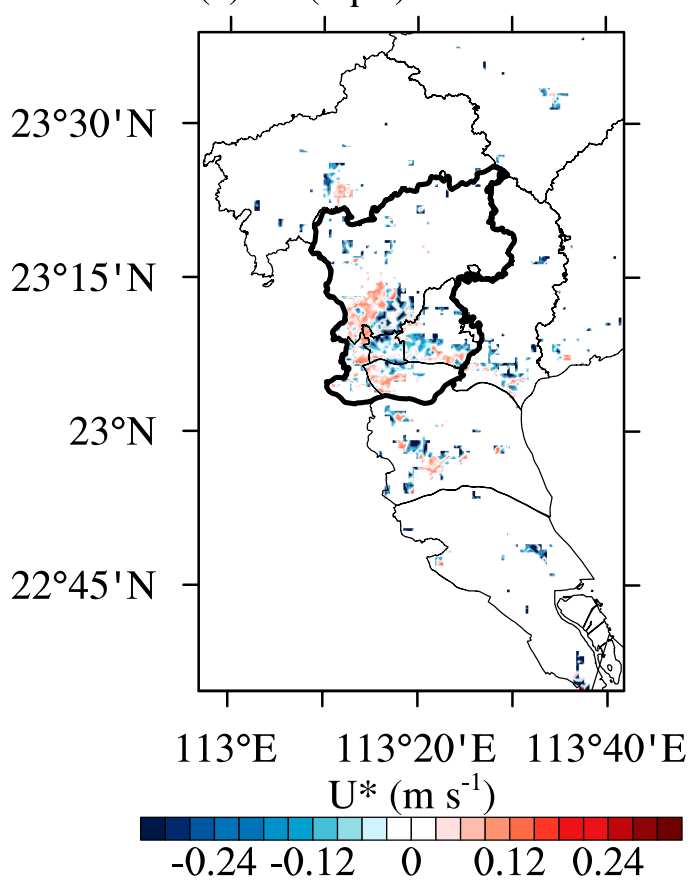

(c) UF(Nov.)

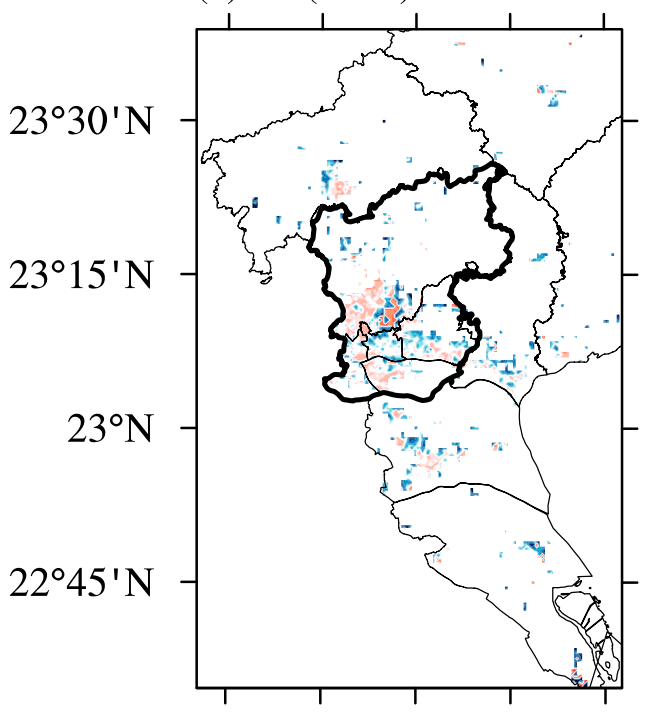

$113^{\circ} \mathrm{E} \quad 113^{\circ} 20^{\prime} \mathrm{E} 113^{\circ} 40^{\prime} \mathrm{E}$

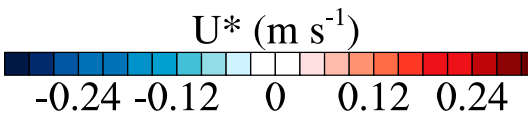

(b) $\mathrm{UM}($ Apr.)

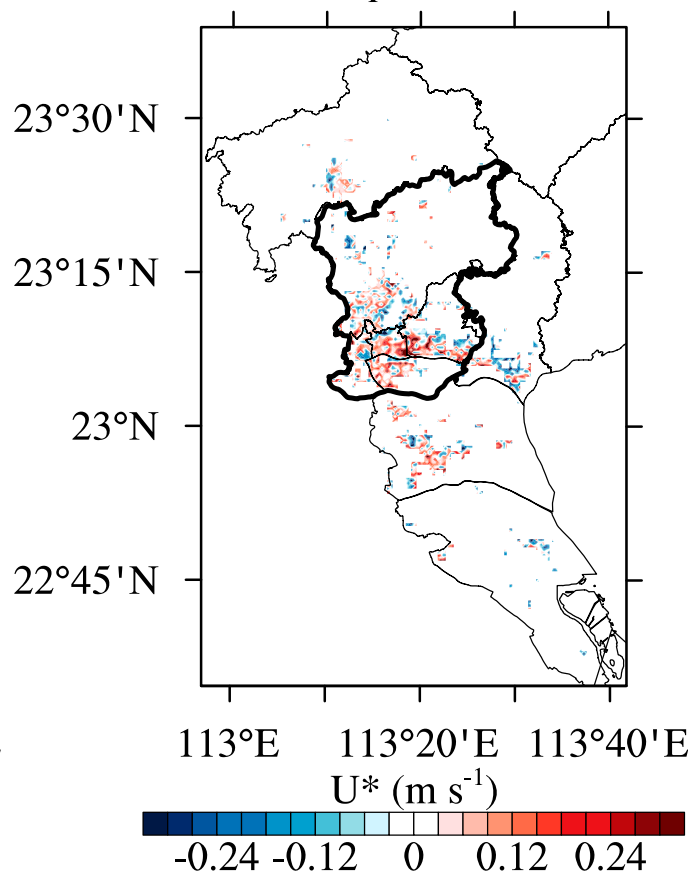

(d) $\mathrm{UM}(\mathrm{Nov}$.

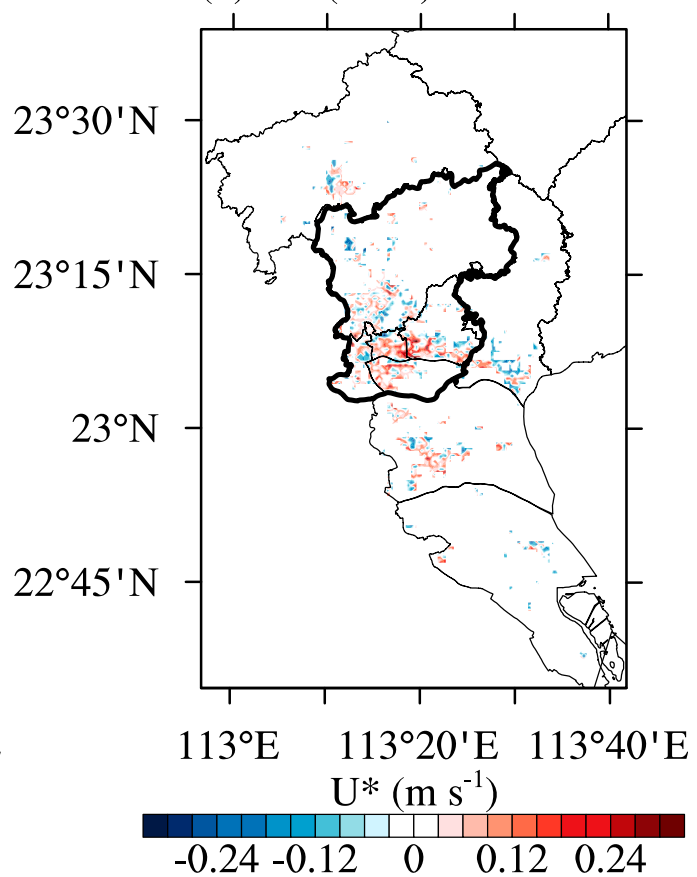

FIG. 6. Impacts of the high-resolution UF and UM on averaged friction velocity $U^{*}$ in April and November. (a),(c) UF (Case 1 - Base), impact of the urban fraction in April and November; (b),(d) UM (Case 2 - Base), impact of the urban morphology in April and November. 
(a) $\mathrm{UF}(\mathrm{Apr}$.)

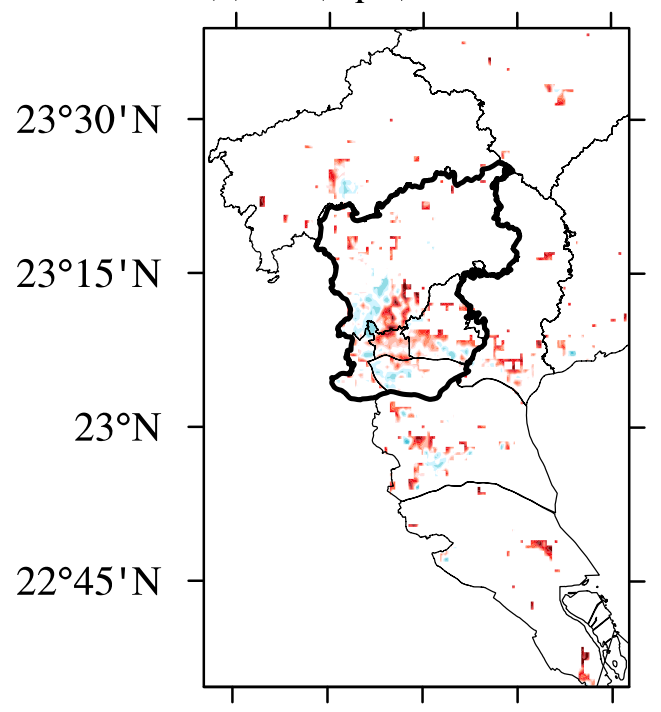

$113^{\circ} \mathrm{E} \quad 113^{\circ} 20^{\prime} \mathrm{E} \quad 113^{\circ} 40^{\prime} \mathrm{E}$

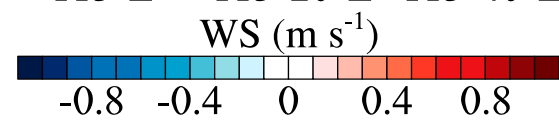

(c) UF(Nov.)

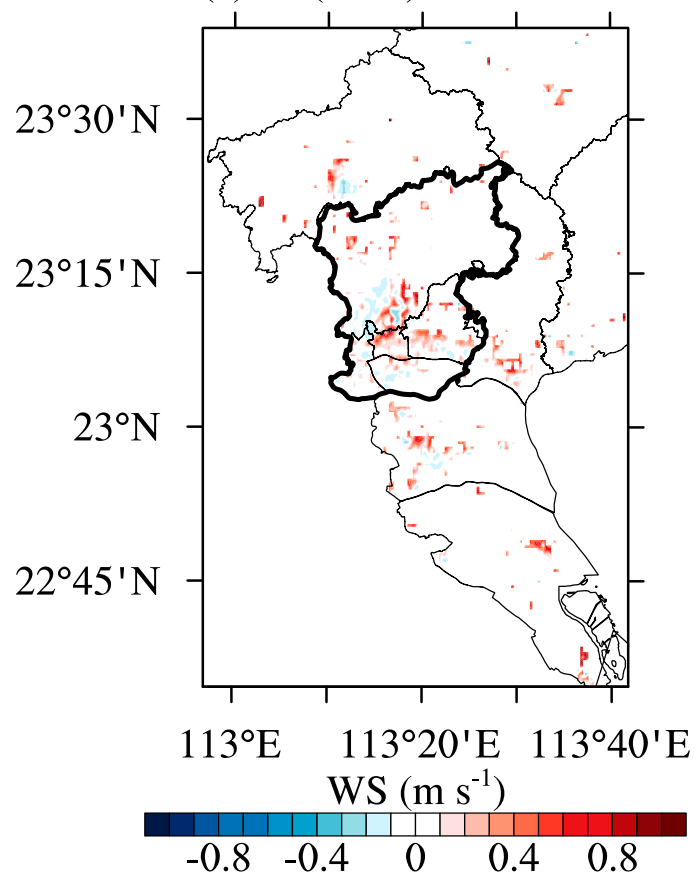

(b) UM(Apr.)

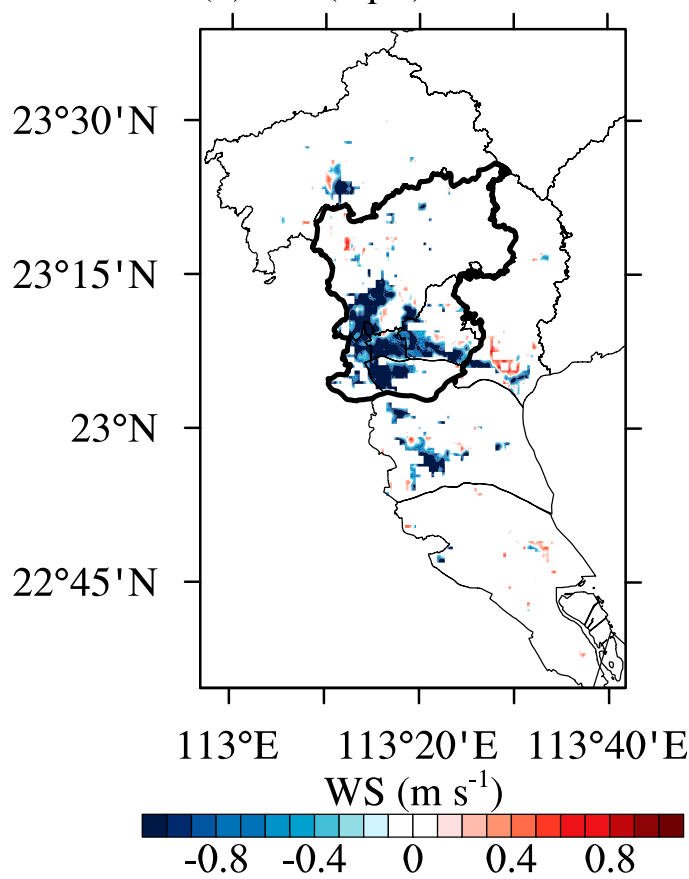

(d) UM(Nov.)

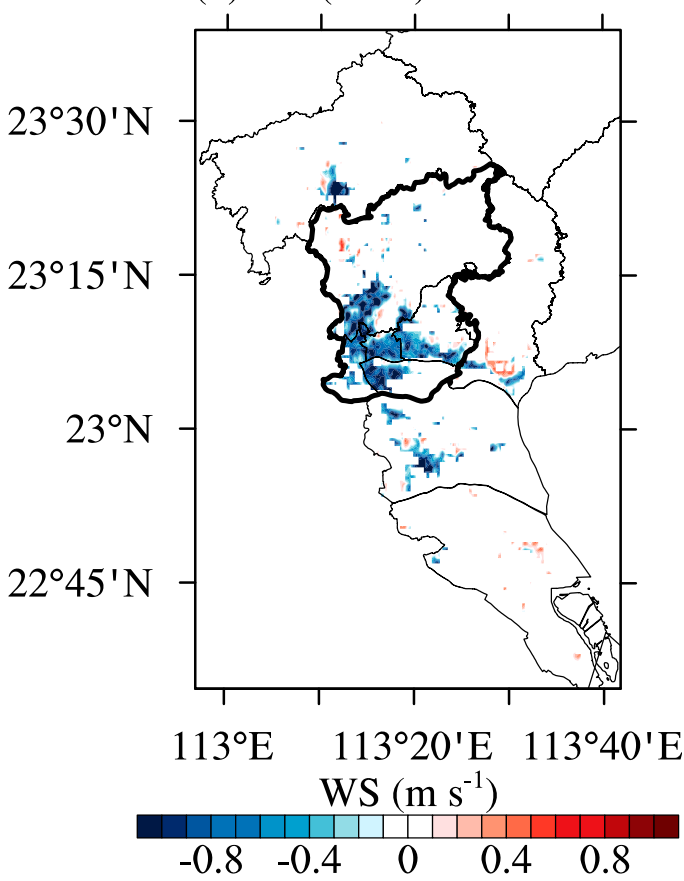

FIG. 7. Impacts of the high-resolution UF and UM on averaged $10-\mathrm{m}$ wind speed (WS) in April and November. (a),(c) UF (Case 1 - Base), impact of the urban fraction in April and November; (b),(d) UM (Case 2 - Base), impact of the urban morphology in April and November. 
(a) UF(Apr.)

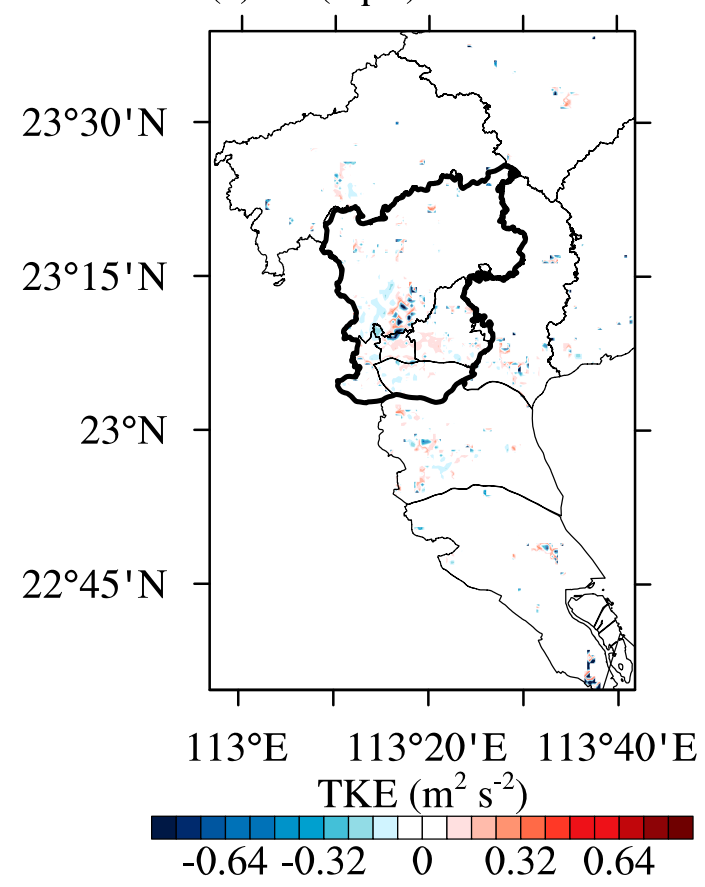

(c) UF(Nov.)

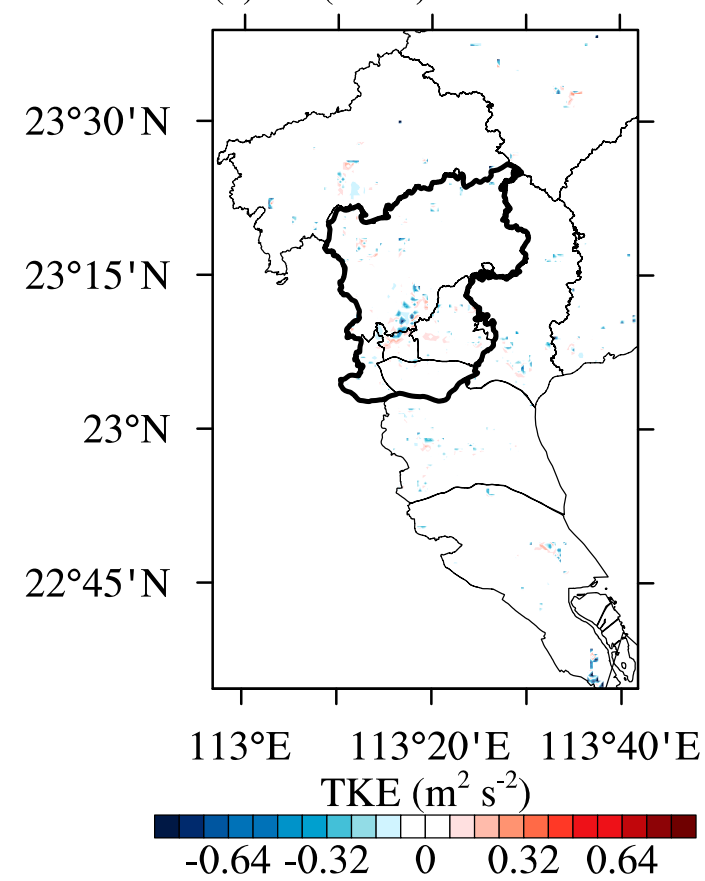

(b) UM(Apr.)

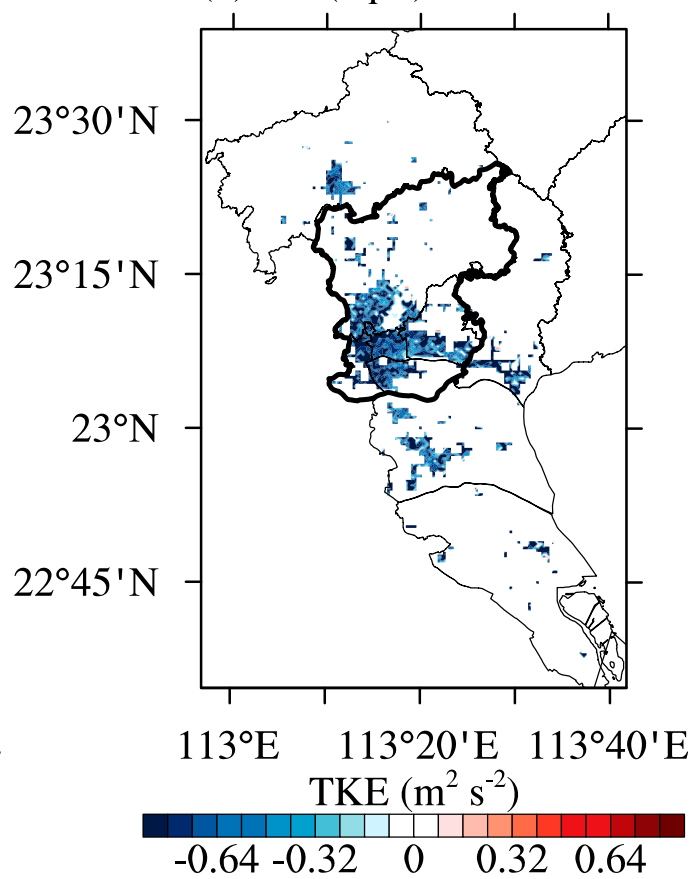

(d) UM(Nov.)

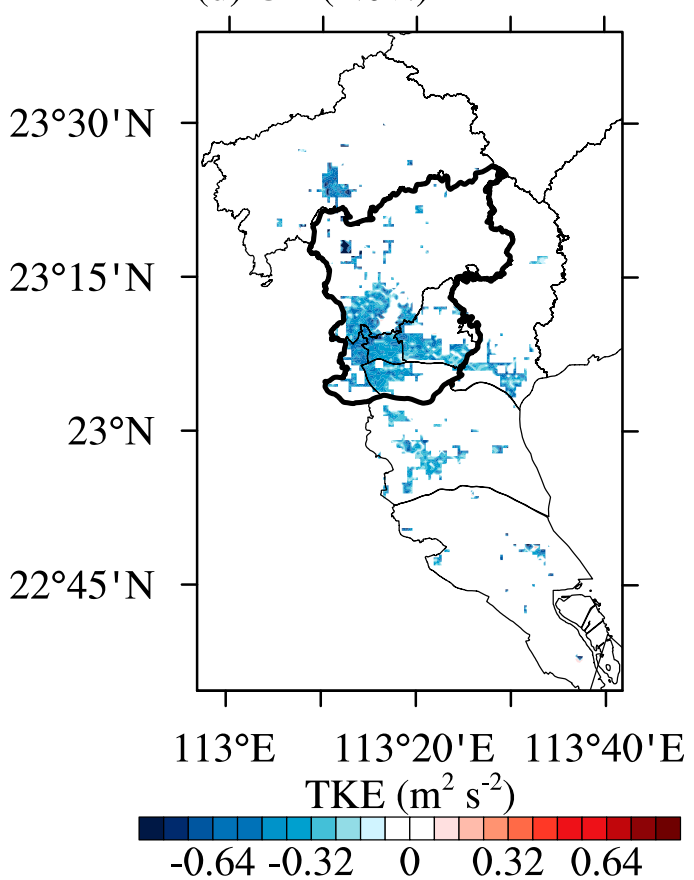

FIG. 8. Impacts of the high-resolution UF and UM on averaged TKE in April and November. (a),(c) UF (Case 1 - Base), impact of the urban fraction in April and November; (b),(d) UM (Case 2 - Base), impact of the urban morphology in April and November. 
field. When the airflow passes through the urban area, the momentum is lost and the wind speed is reduced (Chen and Jiang 2006). The influence of UM on wind speed is more obvious than UF.

It can be seen from Fig. 8 that UF and UM reduce the TKE, and the effect of UM on TKE is more obvious than UF in Guangzhou (UF: $-0.08 \mathrm{~m}^{2} \mathrm{~s}^{-2}$ in April and $-0.06 \mathrm{~m}^{2} \mathrm{~s}^{-2}$ in November; UM: $-0.70 \mathrm{~m}^{2} \mathrm{~s}^{-2}$ in April and $-0.40 \mathrm{~m}^{2} \mathrm{~s}^{-2}$ in November). In the BEP scheme, the effects of vertical and horizontal surfaces in the urban canopy on TKE are calculated. Then this term is multiplied by UF in the Noah LSM. So the reduction of UF produces the decrease of TKE in the urban areas and suburbs. Zhou et al. (2008) found that the expansion of urban area increased the heat flux in the urban areas, and the strong thermal turbulence activity enhanced the transport of the momentum flux and the mechanical turbulence, which resulted in the increase of TKE. On the contrary, the decrease of urban area led to the decrease of TKE. The inclusion of UM also produces the decrease of TKE in the urban areas (April: $0.710 \mathrm{~m}^{2} \mathrm{~s}^{-2}$; November: $0.417 \mathrm{~m}^{2} \mathrm{~s}^{-2}$ ) and suburbs (April: $0.678 \mathrm{~m}^{2} \mathrm{~s}^{-2}$; November: $0.383 \mathrm{~m}^{2} \mathrm{~s}^{-2}$ ). The reason is that the calculation formula of TKE in the urban canopy is related to the area of the walls and roofs. The increase of building surfaces in the urban canopy can produce higher TKE. However, the inclusion of high-resolution UM makes the building surface area to plan area ratio (the maximum value: 5.37 ) lower than the default setting (10.82). That is to say, the UM reduces the building surfaces and results in the reduction of TKE.

In addition to the influences of UCPs on the horizontal distribution of dynamical fields, the vertical sections of wind speed are also analyzed. Figures $9 a-9 d$ show the impacts of UF and UM on the simulated wind section through $23.12^{\circ} \mathrm{N}$ (see the black line in Fig. 3a) in April and November. Figure 9e displays the area-weighted mean building height and standard deviation of building height through $23.12^{\circ} \mathrm{N}$, which passes through LW, YX, TH, and HP. The results show that the vertical section of horizontal wind speed in the urban canopy is less affected by UF (Figs. 9a,c) and mainly affected by UM (Figs. 9b,d). The impacts of UM on the vertical section in the surface layers are more significant. With the increasing of height, the impacts become smaller and smaller. Because of the different heights of buildings (Fig. 9e), the changes of wind speed are also different. At the junction of $\mathrm{YX}$ and $\mathrm{TH}\left(113.30^{\circ}-113.34^{\circ} \mathrm{E}\right)$, the height of wind speed affected by UM is about $400 \mathrm{~m}$, and the most obvious height is below $100 \mathrm{~m}$ because of the taller buildings. But in HP (near $113.4^{\circ} \mathrm{E}$ ), the mean building height and standard deviation of building height are lower, and the height of the wind affected by UM is around $100 \mathrm{~m}$. So the building height and the difference in building height are in good agreement with the vertical section of horizontal wind speed.

\section{c. Effects of high-resolution UCPs on thermal fields}

This section mainly analyzes the influences of UF and UM on the thermal fields. The differences of simulated variables between Case 1 and Base represent the impacts of the high-resolution UF, and the differences between Case 2 and Base represent the impacts of UM. If not considering precipitation or snow (negligible during the study periods), the net radiation flux received by the urban surface is fully converted to sensible heat flux (HFX), latent heat flux (LH), and ground heat flux (GRD). The energy balance equation is

$$
R_{n}=\mathrm{HFX}+\mathrm{LH}+\mathrm{GRD},
$$

where $R_{n}$ is the net radiation, its value being positive with downward direction; HFX and LH have positive values when they are transported from surface to atmosphere, and GRD has positive values when it is transported from soil to surface (Mahrt and Ek 1984; Chen and Dudhia 2001; Xie et al. 2012).

Figure 10 and Table 5 show the impacts of UF (Case 1 - Base) and UM (Case 2 - Base) on the averaged surface skin temperature (TSK) during the daytime and nighttime in April and November. In the daytime, the TSK is affected by both UF and UM, but it is mainly affected by UM at night. The reduction of UF attains the lower TSK, and vice versa, which is due to the change of surface albedo. Similar to $U^{*}$, the calculation of albedo is also divided into two parts: artificial surface and natural surface in the subgrid. In general, the albedo of natural surface (about 0.17-0.22) is higher than that of artificial surface (about 0.14) (Feng and Feng 2012). When UF decreases, the contribution of albedo reduction in artificial surfaces is smaller than that of albedo growth in natural surfaces, so that the total albedo increases in the grids. The surface albedo increases significantly in the region where UF decreases, which results in the reduction of solar radiation that is absorbed by the ground, attaining the lower TSK.

After the addition of UM, the TSK rises obviously during the daytime and nighttime in April and November, especially in the urban areas (daytime: $1.99^{\circ} \mathrm{C}$ in April and $1.77^{\circ} \mathrm{C}$ in November; nighttime: $1.37^{\circ} \mathrm{C}$ in April and $1.35^{\circ} \mathrm{C}$ in November). According to Table 2, it can be seen that the proportion of the urban areas where the building heights are less than the default value $(24 \mathrm{~m})$ is larger than $80 \%$. The decrease of the building height makes the sky-view factor from sky to ground larger than the model default value (0.35) in most areas, and the shading effect of buildings on shortwave radiation 

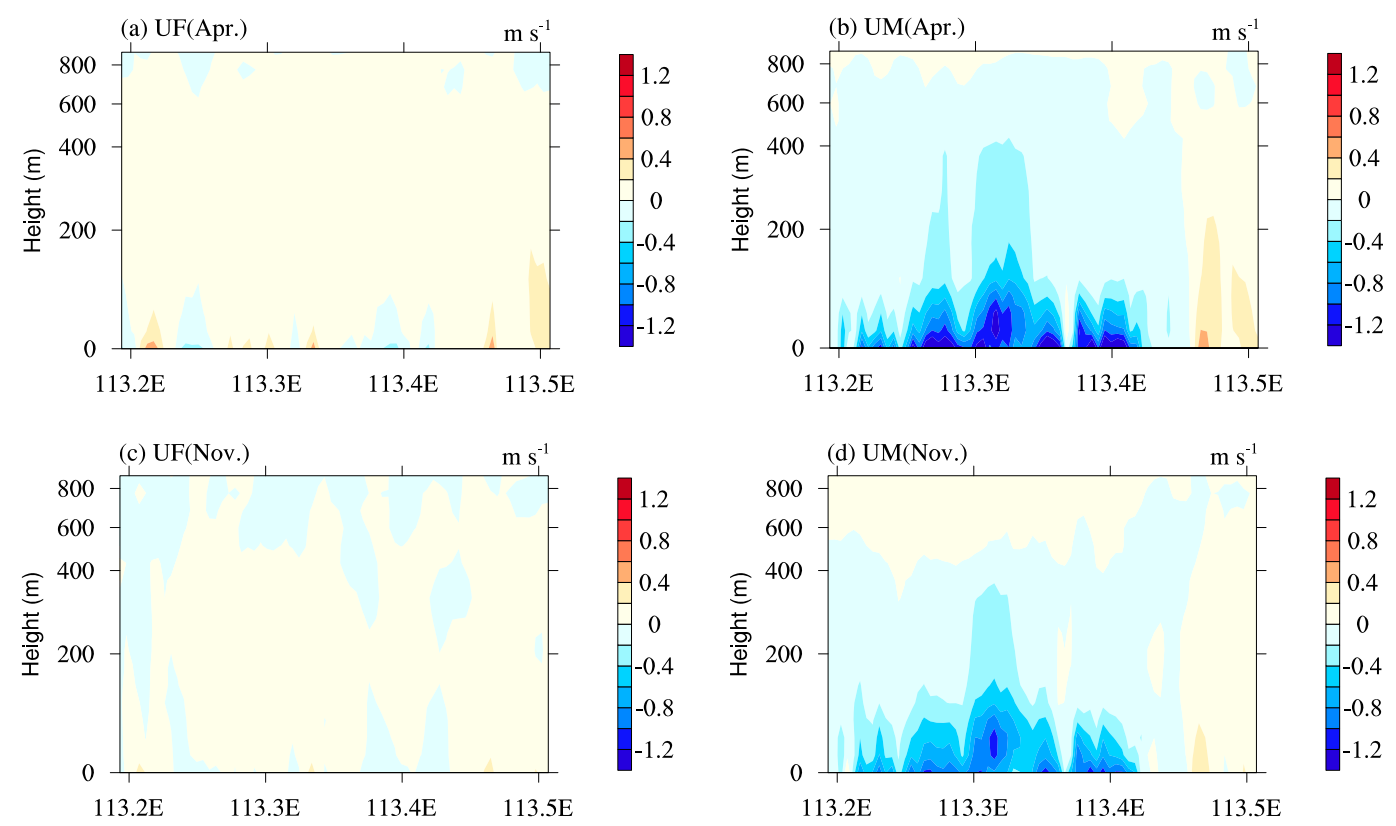

(e)

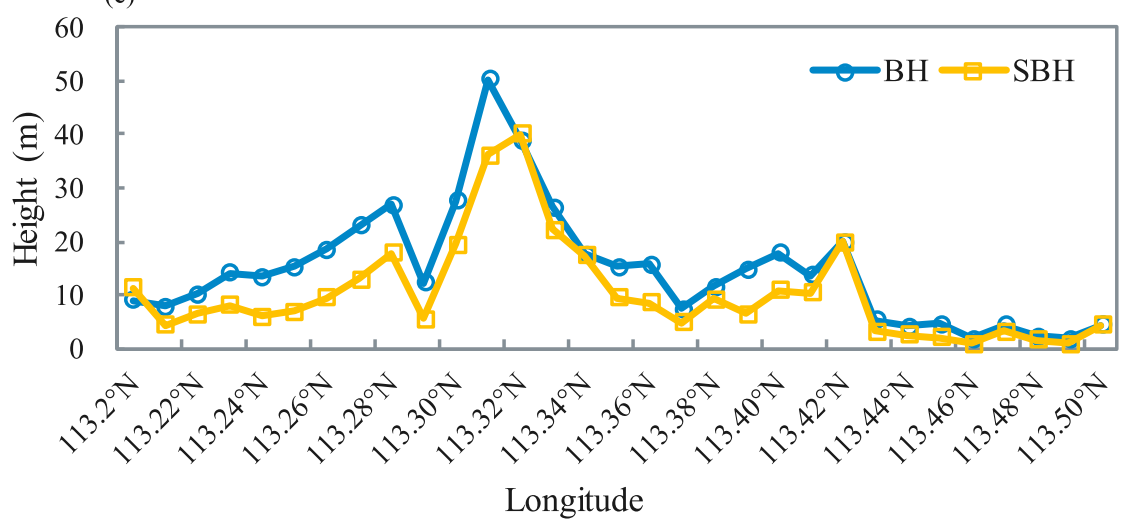

FIG. 9. Impacts of the high-resolution UF and UM on the vertical section of horizontal wind speed through $23.12^{\circ} \mathrm{N}$ in April and November: (a),(c) UF (Case 1 - Base), impact of the urban fraction in April and November; (b),(d) UM (Case 2 - Base), impact of the urban morphology in April and November. (e) The corresponding BH and SBH.

is weakened during the daytime, resulting in an increase of shortwave radiation reaching the ground, which leads to the increase of TSK. In addition, compared with the default building and street width $(20 \mathrm{~m})$, the updated building width and street width are smaller in most urban areas (Fig. 3). Therefore, it can be explained that during the daytime, narrower street canyons more easily trap the heat in the urban canopy but are not conducive to the diffusion of heat because of the lower wind speed, which also results in a higher TSK (Zhang et al. 2002). Under the influences of both the shading and trapping effects of buildings, the TSK has increased. And the rise of TSK at night is related to the change of GRD.

Generally, GRD is negative during the daytime and positive at night. In the daytime, heat is transported from the surface to soil, while heat is transported from the soil to the surface at night. Figure 11 indicates the influences of UF (Case 1 - Base) and UM (Case 2 - Base) on the averaged GRD during the daytime and nighttime in April and November. During the daytime (Figs. 11a,b,e,f), the negative values (blue shadow) represent the increase of GRD, and the positive values (red shadow) represent the decrease. It can be seen from Figs. 11a and 11e that less heat energy is transported from the surface to soil with the reduction of UF. The high-resolution UM (Figs. 11b,f) mainly increases the GRD, which is related to the higher TSK, and more heat flux is transported from the surface to soil. The detailed impacts of UF and UM on energy budgets are calculated and shown in Table 5. During the daytime, the heat transported from the 

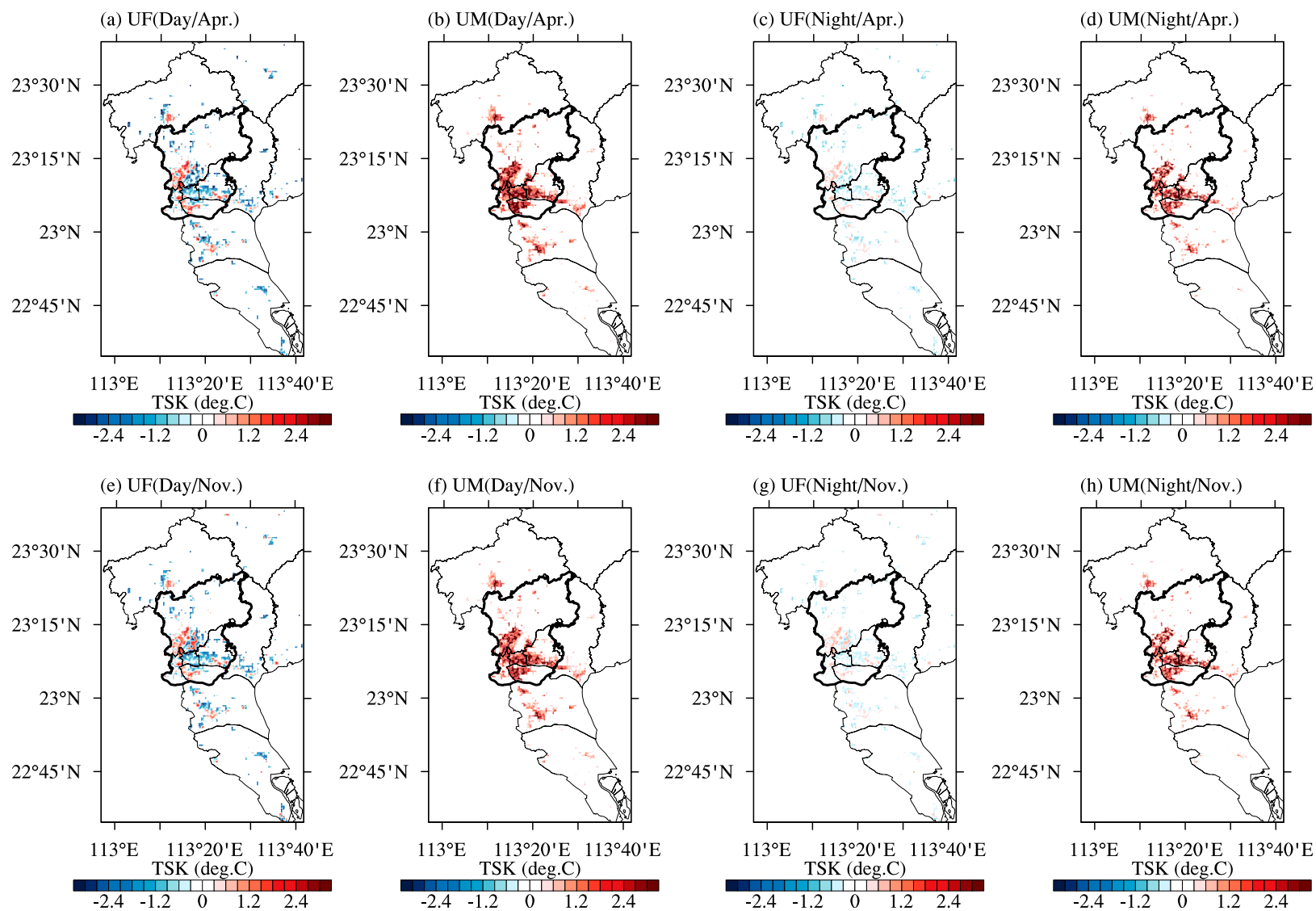

FIG. 10. Impacts of the high-resolution UF and UM on averaged TSK during the daytime and nighttime in April and November. (a),(c),(e),(g) UF (Case 1 - Base), impact of the urban fraction in April and November; (b),(d),(f),(h) UM (Case 2 - Base), impact of the urban morphology in April and November.

surface to soil is reduced in the urban areas (April: $5.17 \mathrm{~W} \mathrm{~m}^{-2}$; November: $4.69 \mathrm{~W} \mathrm{~m}^{-2}$ ) and suburbs (April: $12.81 \mathrm{~W} \mathrm{~m}^{-2}$; November: $12.39 \mathrm{~W} \mathrm{~m}^{-2}$ ) with the decrease of UF, and UM raises the GRD significantly in the urban areas (urban: $13.14 \mathrm{~W} \mathrm{~m}^{-2}$ in April and $8.59 \mathrm{~W} \mathrm{~m}^{-2}$ in
November; suburbs: $4.28 \mathrm{~W} \mathrm{~m}^{-2}$ in April and $2.26 \mathrm{~W} \mathrm{~m}^{-2}$ in November). At night (Figs. 11c,d,g,h), the positive values (red shadow) represent the increase of GRD, and the negative values (blue shadow) represent the decreases. During the nighttime, the effects of UF on the

TABLE 5. Impacts of the high-resolution UF and UM on the energy budget at different areas during the daytime and nighttime in April and November. Daytime is 0700-1800 LT; nighttime is 0000-0600 LT and 1900-2300 LT. Among the variables, GRD is negative in the daytime, where negative values represent an increase, and positive values represent a decrease in the daytime; HFX is negative at night, where negative values represent an increase, and positive values represent a decrease at night.

\begin{tabular}{|c|c|c|c|c|c|c|c|c|c|}
\hline \multirow[b]{3}{*}{ Variable } & \multirow[b]{3}{*}{ Time } & \multicolumn{4}{|c|}{ UF (Case 1 - Base) } & \multicolumn{4}{|c|}{ UM (Case $2-$ Base) } \\
\hline & & \multicolumn{2}{|c|}{ April } & \multicolumn{2}{|c|}{ November } & \multicolumn{2}{|c|}{ April } & \multicolumn{2}{|c|}{ November } \\
\hline & & Urban & Suburbs & Urban & Suburbs & Urban & Suburbs & Urban & Suburbs \\
\hline \multirow[t]{2}{*}{$\operatorname{TSK}\left({ }^{\circ} \mathrm{C}\right)$} & Daytime & -0.44 & -1.10 & -0.40 & -0.95 & 1.99 & 0.86 & 1.77 & 0.81 \\
\hline & Nighttime & -0.15 & -0.40 & -0.09 & -0.28 & 1.37 & 0.49 & 1.35 & 0.53 \\
\hline \multirow[t]{2}{*}{$\operatorname{GRD}\left(\mathrm{W} \mathrm{m}^{-2}\right)$} & Daytime & 5.17 & 12.81 & 4.69 & 12.39 & -13.14 & -4.28 & -8.59 & -2.26 \\
\hline & Nighttime & -0.92 & -2.10 & -0.96 & -1.60 & 1.87 & 1.69 & 2.59 & 1.77 \\
\hline \multirow[t]{2}{*}{$\operatorname{HFX}\left(\mathrm{W} \mathrm{m}^{-2}\right)$} & Daytime & -18.04 & -50.26 & -14.17 & -34.92 & -28.29 & -8.30 & -22.14 & -5.96 \\
\hline & Nighttime & -0.65 & -2.96 & -0.05 & -0.05 & -6.20 & -1.05 & -5.30 & -1.28 \\
\hline \multirow[t]{2}{*}{$\mathrm{LH}\left(\mathrm{W} \mathrm{m}^{-2}\right)$} & Daytime & 21.99 & 61.56 & 13.22 & 43.15 & -0.16 & 0.42 & 0.25 & 0.76 \\
\hline & Nighttime & 1.21 & 3.53 & 0.52 & 1.12 & 0.48 & 0.06 & 0.24 & 0.02 \\
\hline
\end{tabular}


(a) UF(Day/Apr.)

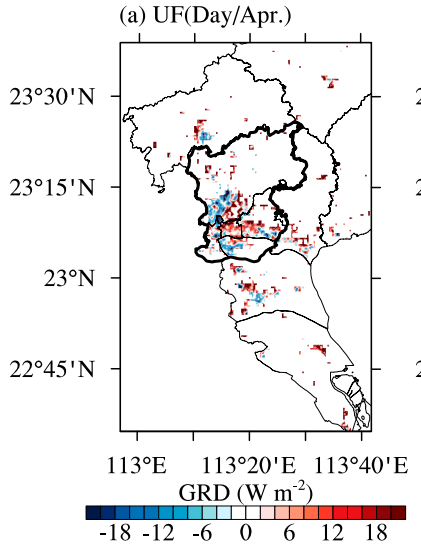

(e) UF(Day/Nov.)

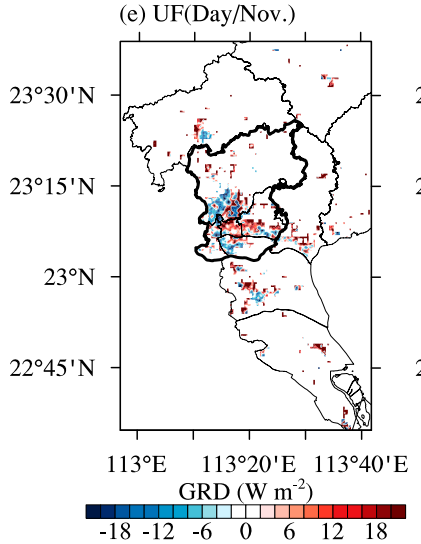

(b) UM(Day/Apr.)

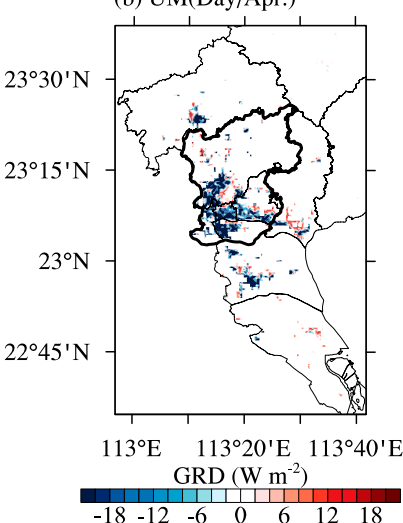

$\begin{array}{llllllll}-18 & -12 & -6 & 0 & 6 & 12 & 18\end{array}$

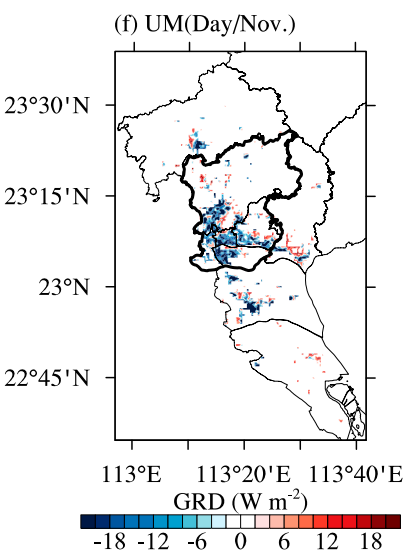

(c) UF(Night/Apr.)

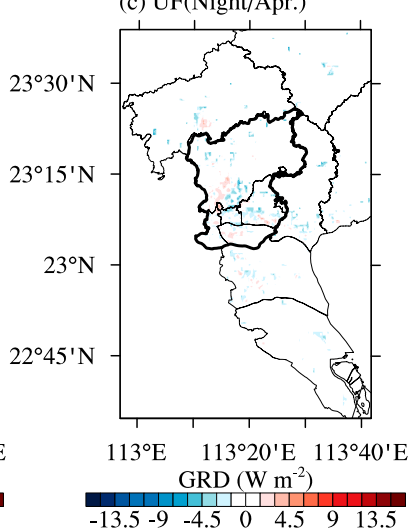

(g) UF(Night/Nov.)

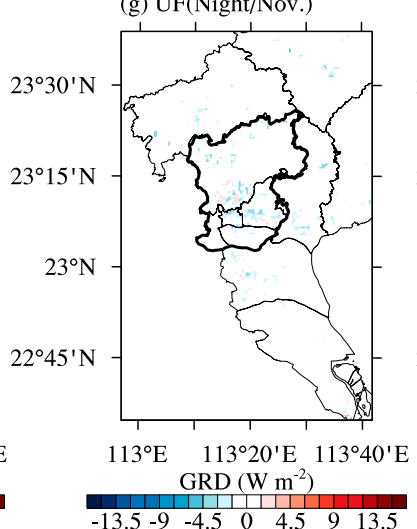

(d) UM(Night/Apr.)

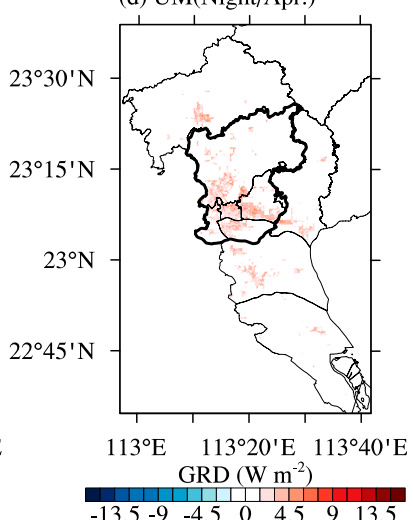

(h) UM(Night/Nov.)

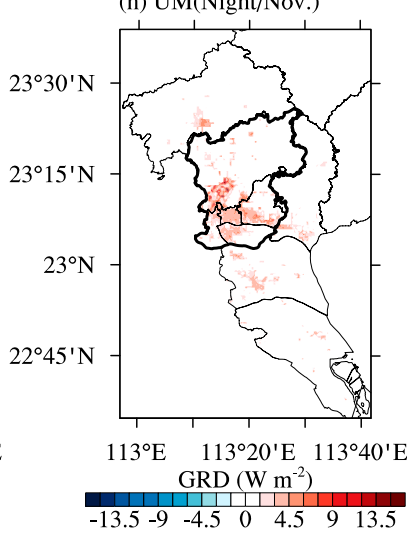

FIG. 11. Impacts of the high-resolution UF and UM on averaged GRD during the daytime and nighttime in April and November. (a),(c),(e),(g) UF (Case 1 - Base), impact of the urban fraction in April and November; (b),(d),(f),(h) UM (Case 2 - Base), impact of the urban morphology in April and November.

GRD (Figs. 11c,g) are smaller compared with UM (Figs. 11d,h). As UM induces larger storage heat in the soil during the daytime, the heat transported from the soil to the surface also increases significantly at night. In other words, more heat flux is transported from the soil to surface, producing an increase of the TSK during the nighttime. There is a positive feedback effect between GRD and TSK.

HFX is usually positive in the daytime and negative at night. That is to say, the positive values (red shadow) represent the increase and the negative values (blue shadow) represent the decrease during the daytime in Figs. 12a, 12b, 12e, and 12f; the negative values (blue shadow) represent the increase and the positive values (red shadow) represent the decrease during the nighttime in Figs. 12c, 12d, 12g, and 12h. The effects of UF (Case 1 Base) and UM (Case 2 - Base) on the HFX in the daytime are greater than those at night during April and November. In the daytime, the increase (decrease) of UF induces higher (lower) HFX. At night, the influence of UF on HFX can be ignored (Figs. 12c,g). UM causes the HFX to decrease (urban: $28.29 \mathrm{~W} \mathrm{~m}^{-2}$ in April and $22.14 \mathrm{~W} \mathrm{~m}^{-2}$ in
November; suburbs: $8.30 \mathrm{~W} \mathrm{~m}^{-2}$ in April and $5.96 \mathrm{~W} \mathrm{~m}^{-2}$ in November) during the daytime, and increase (urban: $6.20 \mathrm{~W} \mathrm{~m}^{-2}$ in April and $5.30 \mathrm{~W} \mathrm{~m}^{-2}$ in November; suburbs: $1.05 \mathrm{~W} \mathrm{~m}^{-2}$ in April and $1.28 \mathrm{~W} \mathrm{~m}^{-2}$ in November) during the nighttime. The effect of UM on HFX is more obvious in the urban areas than in the suburbs.

It is difficult to analyze how UF and UM affect the HFX only from the spatial distribution results, thus the calculation formula of HFX in Noah LSM is given (Xie et al. 2012):

$$
\mathrm{HFX}=\rho C_{p} C_{h} U\left(\theta_{\mathrm{sfc}}-\theta\right) \propto U(\mathrm{TSK}-\mathrm{T} 2),
$$

where $\rho$ is the air density, $C_{p}$ is the specific heat capacity, $C_{h}$ is the surface heat exchange coefficient, $\theta_{\mathrm{sfc}}$ is the surface potential temperature, $U$ and $\theta$ are atmospheric wind speed and potential temperature at the lowest model layer, respectively, and TSK and T2 are the surface skin temperature and 2-m temperature, respectively (Mahrt and Ek 1984; Chen and Dudhia 2001).

The surface heat exchange coefficients are similar in the Base, Case 1, and Case 2 experiments, which are 

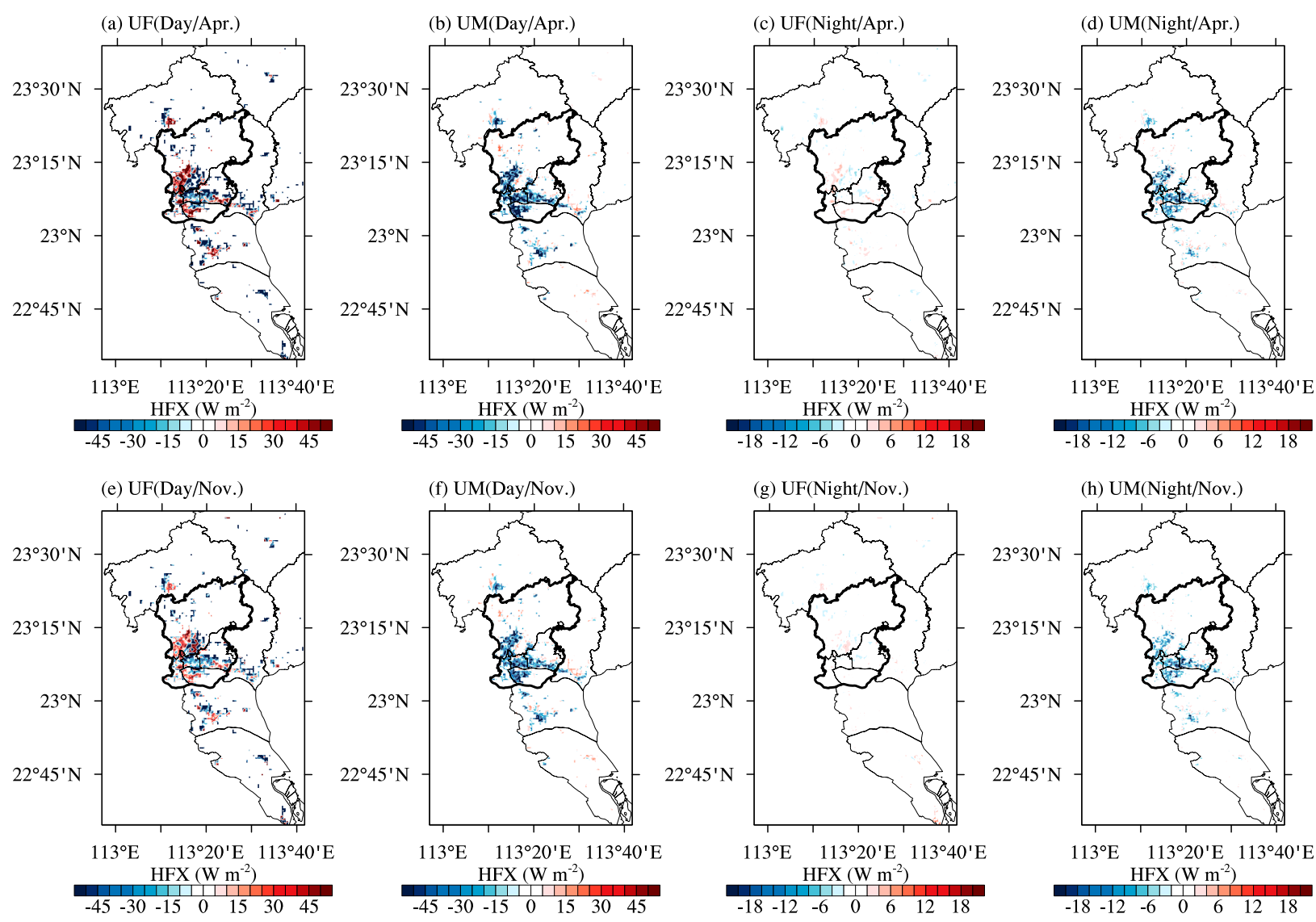

FIG. 12. Impacts of the high-resolution UF and UM on averaged HFX during the daytime and nighttime in April and November. (a),(c),(e),(g) UF (Case 1 - Base), impact of the urban fraction in April and November; (b),(d),(f),(h) UM (Case 2 - Base), impact of the urban morphology in April and November.

provided by the same surface-layer scheme. The terms $C_{p}$ and $\rho$ are constant. This implies that HFX is primarily dependent on the near-surface temperature gradient and surface wind speed. The impacts of updated UF (Case 1 - Base) and UM (Case 2 - Base) on the mean time series of the near-surface temperature gradient (TSK - T2), the near-surface temperature gradient multiplied by surface horizontal wind speed $[U(\mathrm{TSK}-\mathrm{T} 2)]$, and HFX in the urban areas and suburbs during November are shown in Fig. 13. The effects of UF on HFX are closely related to the nearsurface temperature gradient in the urban areas and suburbs. The impact of UF on the 2-m temperature is very small (Table 4). Thus, the effect of UF on HFX (Fig. 12e) is almost consistent with TSK (Fig. 10e). The effects of UM and UF on HFX are different; UM has a great influence on wind speed, therefore the influence of surface wind speed cannot be neglected, when considering the impact of UM on HFX. Figures 13b and $13 \mathrm{~d}$ show UM influences HFX by the near-surface temperature gradient and surface wind speed in the urban areas and suburbs. UM produces higher TSK in the urban areas and suburbs (Figs. 10f,h), the change of 2-m temperature is not obvious, and the nearsurface temperature gradient increases, but an obvious decrease in wind speed (Fig. 8d) reduces the heat transferred between the ground and the air, which finally results in negative HFX (Figs. 12f,h and 13b,d). The results in April are similar with those in November.

The effect of UF (Case 1 - Base) on LH is mainly reflected in the daytime, and the impact of UM (Case 2 - Base) on LH can be neglected (Table 5). The LH in the WRF Model is determined by the water vapor flux. The increase of UF raises the urban impermeable surface and reduces the natural underlying surface, which produces the decrease of water vapor (Shi et al. 2011). Thus, the increase of UF (i.e., the increase of the urban underlying surface) may enhance the dry island effect (Lokoshchenko 2017; S. Zhang et al. 2010; Wang and Gong 2010) and weaken LH, while UF reduction induces the increase of LH (figure omitted). 
(a) Urban UF (Case1-Base)

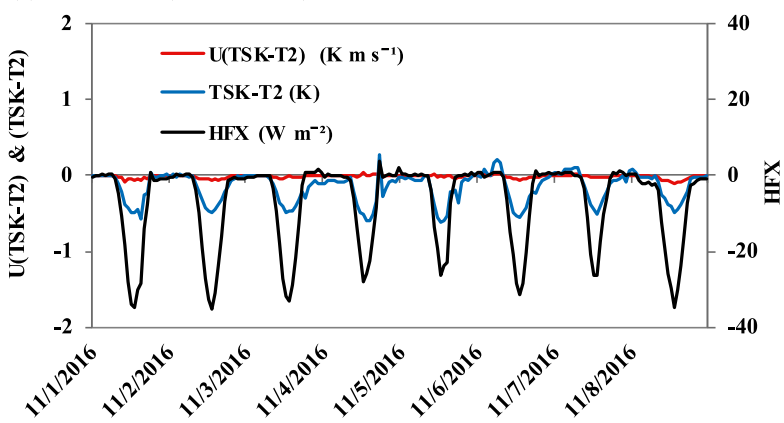

(c) Suburbs UF (Case1-Base)

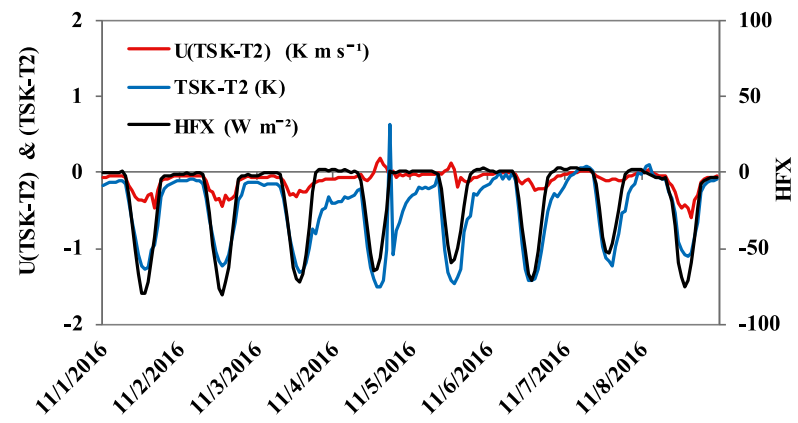

(b) Urban UM (Case2-Base)

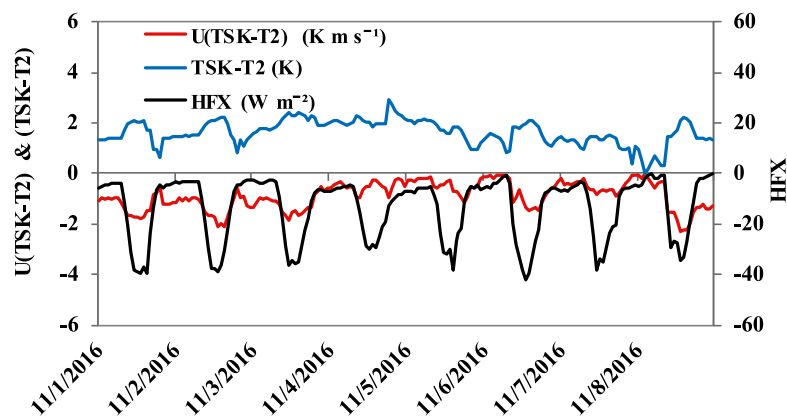

(d) Suburbs UM (Case2-Base)

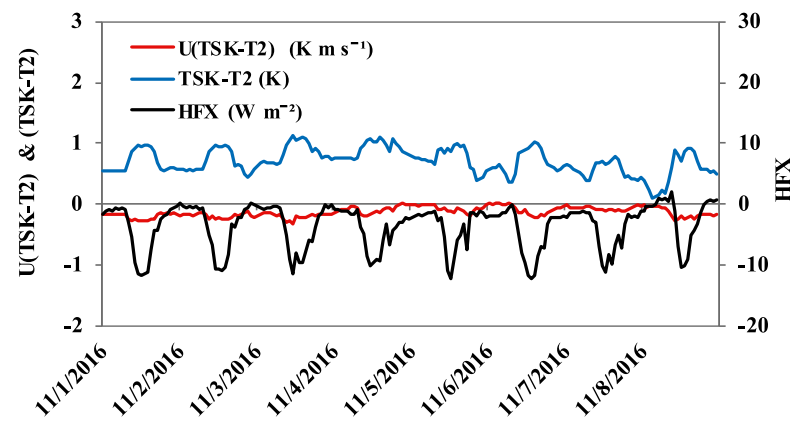

FIG. 13. Mean time series of impacts of the UF and UM on TSK - T2, $U(\mathrm{TSK}-\mathrm{T} 2)$, and HFX in the urban areas and suburbs in November: (a) impact of UF (Case 1 - Base) in the urban areas; (b) impact of UM (Case 2 - Base) in the urban areas; (c) impact of UF (Case 1 - Base) in the suburbs; (d) impact of UM (Case 2 - Base) in the suburbs.

\section{Summary and conclusions}

This study analyzes the impacts of finescale UCPs on dynamical and thermal fields over Guangzhou in wet (April) and dry (November) seasons, using the WRF Model coupled with the Noah LSM and BEP scheme at high horizontal resolution $(500 \mathrm{~m})$. The simulation performances of four experiments, including default UCPs (Base), only updated UF (Case 1), only updated UM (Case 2), and both updated UF and UM (Case 3), are evaluated in the urban areas and suburbs. It is found that the finescale UF and UM data in the model have little impact on the simulated $\mathrm{T} 2$ and $\mathrm{RH}$ and have an obvious improvement on the simulations of wind environment in the urban areas, especially when only high-resolution $\mathrm{UM}$ is considered: the deviation between the simulations and observations changes from $2.30 \mathrm{~m} \mathrm{~s}^{-1}$ (Base) to $1.61 \mathrm{~m} \mathrm{~s}^{-1}$ (Case 2) in April and from $1.30 \mathrm{~m} \mathrm{~s}^{-1}$ (Base) to $0.77 \mathrm{~m} \mathrm{~s}^{-1}$ (Case 2) in November. The simulation with the high resolution $(500 \mathrm{~m})$ has a significant meaning on guiding modeling studies at urban scales in the future.

The effects of the high-resolution UF and UM on the dynamical fields are then analyzed, including $U^{*}$, horizontal and vertical wind fields, and TKE. For $U^{*}$, it is affected by both UF and UM. The increase of UF raises
$U^{*}$ and vice versa. The UM makes $U^{*}$ increase more significantly in the urban areas than the suburbs because of more obvious urban morphology differences in the urban areas, which enhances the surface roughness. For the wind speed, the influence of UM on wind speed is greater than UF, and the wind speed reduces more obviously in the urban areas than in the suburbs. The vertical section of horizontal wind speed in the urban canopy is mainly affected by UM. And the vertical sections of horizontal wind speed are varied owing to the varied building heights in each district (e.g., the junction of YX and TH: $\sim 400 \mathrm{~m}$; HP: $\sim 100 \mathrm{~m}$ ). TKE is also mainly affected by UM. The inclusion of UM produces the decrease of TKE in the urban areas and suburbs.

In addition to the dynamical fields, the thermal fields (TSK, GRD, HFX, and LH) are also analyzed. There is a positive feedback effect between GRD and TSK. The increasing UF makes the surface albedo decrease, causing more solar radiation to be absorbed by the ground, and then the TSK increases. The larger sky-view factor weakens the shading effect of buildings on shortwave radiation, and the larger building packing density (e.g., UM factors with narrower streets and higher-density buildings) is also conducive to trap more heat in the urban canopy, which lead to the higher TSK 
during the daytime in April and November. The increase of TSK results in GRD's rising in the daytime, indicating more heat transport from the surface to soil. At night, more heat is transported from the soil to the surface and results in an increase of TSK. For HFX, the increase of UF causes HFX to increase during the daytime, while the influence can be ignored at night in April and November. The high-resolution UM results in a decrease of HFX in the daytime and an increase at night. The effect of UM on HFX is more obvious in the urban areas than in the suburbs. The effect of UF on HFX is closely related to the near-surface temperature gradient and is consistent with the TSK affected by UF. Besides the near-surface temperature gradient, UM also influences the HFX by the surface wind speed. For LH, it is mainly affected by UF in the daytime. Larger UF attains lower LH in the daytime, which enhances the dry island effect.

In the future, we will establish localized anthropogenic heat emissions and study the effects of local nonuniform high-resolution urban canopy parameters and anthropogenic heat emissions on dynamical and thermal fields in the WRF Model coupled with the Noah LSM and SLUCM scheme. Meanwhile, the influence of highresolution urban canopy parameters on atmospheric pollutants will be considered in combination with refined pollution emission sources. It is hoped that the results can provide support for further studies on the urban ventilation, urban heat island, and urban atmospheric environment.

Acknowledgments. This work is supported by the National Key R\&D Program of China (2017YFC0210105 and 2016YFC0202206), National Natural Science Foundation (91544102 and 91644215), the China Special Fund for Meteorological Research in the Public Interest (GYHY201406031), the Science and Technology Planning Project of Guangzhou (201604020028), the Science and Technology Planning Project of China (2014BAC21B02), the National Key R\&D Program of China (2016YFC0203600 and 2016YFC0203305), National Nature Science Fund for Distinguished Young Scholars (41425020), and the Science and Technology program of Guangzhou (201707010475). This work is also partly supported by the high-performance grid-computing platform of Sun Yat-sen University.

\section{REFERENCES}

Adachi, S. A., F. Kimura, H. Kusaka, M. G. Duda, Y. Yamagata, H. Seya, K. Nakamichi, and T. Aoyagi, 2014: Moderation of summertime heat island phenomena via modification of the urban form in the Tokyo Metropolitan Area. J. Appl. Meteor. Climatol., 53, 1886-1900, https://doi.org/10.1175/JAMC-D-130194.1.
Burian, S. J., A. McKinnon, J. Hartman, and W. S. Han, 2005: Urban Morphological Analysis Processor User Manual version 2.0. Department of Civil and Environmental Engineering, University of Utah, 34 pp.

Chang, M., S. Fan, and X. Wang, 2014: Impact of refined land-cover data on WRF performance over the Pearl River Delta region, China (in Chinese). Acta Sci. Circumstantiae, 34, 1922-1933.

Chen, F., and J. Dudhia, 2001: Coupling an advanced land surface hydrology model with the Penn State-NCAR MM5 modeling system. Part I: Model implementation and sensitivity. Mon. Wea. Rev., 129, 569-585, https://doi.org/10.1175/1520-0493(2001) 129<0569:CAALSH > 2.0.CO;2.

_ , and Coauthors, 2011b: The integrated WRF/urban modelling system: Development, evaluation, and applications to urban environmental problems. Int. J. Climatol., 31, 273-288, https:// doi.org/10.1002/joc.2158.

— S. Miao, M. Tewari, J.-W. Bao, and H. Kusaka, 2011a: A numerical study of interactions between surface forcing and sea-breeze circulations and their effects on stagnant winds in the greater Houston area. J. Geophys. Res., 116, D12105, https://doi.org/10.1029/2010JD015533.

_, X. Yang, and J. Wu, 2016: Simulation of the urban climate in a Chinese megacity with spatially heterogeneous anthropogenic heat data. J. Geophys. Res. Atmos., 121, 5193-5212, https://doi.org/10.1002/2015JD024642.

Chen, Y., and W. Jiang, 2006: The numerical experiments of the effect of urban buildings on boundary layer structure (in Chinese). Plateau Meteor., 25, 824-833.

Ching, J., and Coauthors, 2009: National Urban Database and Access Portal Tool. Bull. Amer. Meteor. Soc., 90, 1157-1168, https://doi.org/10.1175/2009BAMS2675.1.

_ canopy modeling for weather climate and air quality applications. 11th Symp. on the Urban Environment, Atlanta, GA, Amer. Meteor. Soc., J1.3, https://ams.confex.com/ams/94Annual/ webprogram/Manuscript/Paper236443/ExtAbs.WUDAPT.pdf.

_- , and Coauthors, 2018: WUDAPT: An urban weather, climate, and environmental modeling infrastructure for the Anthropocene. Bull. Amer. Meteor. Soc., 99, 1907-1924, https://doi.org/10.1175/BAMS-D-16-0236.1.

de la Paz, D., R. Borge, and A. Martilli, 2016: Assessment of a high resolution annual WRF-BEP/CMAQ simulation for the urban area of Madrid (Spain). Atmos. Environ., 144, 282-296, https:// doi.org/10.1016/j.atmosenv.2016.08.082.

Fallmann, J., R. Forkel, and S. Emeis, 2016: Secondary effects of urban heat island mitigation measures on air quality. Atmos. Environ., 125, 199-211, https://doi.org/10.1016/j.atmosenv.2015.10.094.

Feddema, J. J., K. W. Oleson, G. B. Bonna, L. O. Mearns, L. E. Buja, G. A. Meehl, and W. M. Washington, 2005: The importance of land-cover change in simulating future climates. Science, $\mathbf{3 1 0}$, 1674-1678, https://doi.org/10.1126/science.1118160.

Feng, Y., and H. Feng, 2012: TM data retrieval and analysis of Beijing area surface albedo (in Chinese). Sci. Surv. Mapp., 37, 166-168.

Glotfelty, T., M. Tewari, K. Sampson, M. Duda, F. Chen, and J. Ching, 2013: NUDAPT 44 Documentation. NCAR Research Applications Laboratory Doc., 9 pp., https://ral.ucar.edu/sites/default/ files/public/product-tool/NUDAPT_44_Documentation.pdf.

Guangzhou Municipal Peoples Government, 2016: The ecological civilization construction in Guangzhou (2016-2020). Accessed 10 August 2016, http://www.gz.gov.cn/gzgov/s2811/201608/ 1c0082b3d2224dd5aa7eb7d0cd32fd2e.shtml.

Guarino, M. V., A. Martilli, S. D. Sabatino, and L. S. Leo, 2014: Modelling the urban boundary-layer over a typical Mediterranean 
city using WRF: Assessment of UHI and thermal comfort. Proc. Fourth Joint US-European Fluids Engineering Division Summer Meeting/12th Int. Conf. on Nanochannels, Microchannels, and Minichannels, Chicago, IL, ASME, V01DT28A006, https:// doi.org/10.1115/FEDSM2014-21572.

He, X., Y. Li, X. Wang, L. Chen, B. Yu, Y. Zhang, and S. Miao, 2019: High-resolution dataset of urban canopy parameters for Beijing and its application to the integrated WRF/Urban modelling system. J. Cleaner Prod., 208, 373-383, https:// doi.org/10.1016/j.jclepro.2018.10.086.

Jian, M., 1994: The division of seasons for the south China region (in Chinese). Acta Sci. Nat. Univ. Sunyatseni, 33, 131-133.

Jiang, L., L. Yu, Y. Qin, and Z. Wang, 2016: Effect of urban canopy scheme on the weather simulation research in Beijing area (in Chinese). J. Civ. Aviat. Flight Univ. China, 27, 20-26.

Kusaka, H., and F. Kimura, 2004: Coupling a single-layer urban canopy model with a simple atmospheric model: Impact on urban heat island simulation for an idealized case. J. Meteor. Soc. Japan, 82, 67-80, https://doi.org/10.2151/jmsj.82.67.

- K. Kondo, Y. Kikegawa, and F. Kimura, 2001: A simple singlelayer urban canopy model for atmospheric models: Comparison with multi-layer and slab models. Bound.-Layer Meteor., 101, 329-358, https://doi.org/10.1023/A:1019207923078.

Lee, S.-H., and Coauthors, 2011: Evaluation of urban surface parameterizations in the WRF model using measurements during the Texas Air Quality Study 2006 field campaign. Atmos. Chem. Phys., 11, 2127-2143, https://doi.org/10.5194/acp-11-2127-2011.

Li, D., E. Bou-Zeid, M. Barlage, F. Chen, and J. A. Smith, 2013: Development and evaluation of a mosaic approach in the WRF-Noah framework. J. Geophys. Res. Atmos., 118, 11918 11935, https://doi.org/10.1002/2013JD020657.

Liao, J., T. Wang, X. Wang, M. Xie, Z. Jiang, X. Huang, and J. Zhu, 2014: Impacts of different urban canopy schemes in WRF/ Chem on regional climate and air quality in the Yangtze River Delta, China. Atmos. Res., 145-146, 226-243, https://doi.org/ 10.1016/j.atmosres.2014.04.005.

Lin, W., L. Zhang, D. Du, and L. Yang, 2009: Quantification of land use/land cover changes in Pearl River Delta and its impact on regional climate in summer using numerical modeling. Reg. Environ. Change, 9, 75-82, https://doi.org/ 10.1007/s10113-008-0057-5.

Liu, Y., F. Chen, T. Warner, and J. Basara, 2006: Verification of a mesoscale data-assimilation and forecasting system for the Oklahoma City area during the Joint Urban 2003 Field Project. J. Appl. Meteor., 45, 912-929, https://doi.org/10.1175/ JAM2383.1.

Lokoshchenko, M. A., 2017: Urban heat island and urban dry island in Moscow and their centennial changes. J. Appl. Meteor. Climatol., 56, 2729-2745, https://doi.org/10.1175/JAMC-D-160383.1.

Loridan, T., and C. S. B. Grimmond, 2012: Characterization of energy flux partitioning in urban environments: Links with surface seasonal properties. J. Appl. Meteor. Climatol., 51, 219-238, https://doi.org/10.1175/JAMC-D-11-038.1.

— , F. Lindberg, O. Jorba, S. Kotthaus, C. S. Grossman, and C. S. B. Grimmond, 2013: High resolution simulation of the variability of surface energy balance fluxes across central London with urban zones for energy partitioning. Bound.Layer Meteor., 147, 493-523, https://doi.org/10.1007/s10546013-9797-y.

Mahrt, L., and M. Ek, 1984: The influence of atmospheric stability on potential evaporation. J. Climate Appl. Meteor., 23, 222-234, https:// doi.org/10.1175/1520-0450(1984)023<0222:TIOASO >2.0.CO;2.
Martilli, A., A. Clappier, and M. W. Rotach, 2002: An urban surface exchange parameterization for mesoscale models. Bound.-Layer Meteor., 104, 261-304, https://doi.org/10.1023/ A:1016099921195.

—, Y. A. Roulet, M. Junier, F. Kirchner, M. W. Rotach, and A. Clappier, 2003: On the impact of urban surface exchange parameterisations on air quality simulations: the Athens case. Atmos. Environ., 37, 4217-4231, https://doi.org/10.1016/ S1352-2310(03)00564-8.

Miao, S., F. Chen, M. A. LeMone, M. Tewari, Q. Li, and Y. Wang, 2009a: An observational and modeling study of characteristics of urban heat island and boundary layer structures in Beijing. J. Appl. Meteor. Climatol., 48, 484-501, https://doi.org/10.1175/2008JAMC1909.1.

,,-- Q. Li, and S. Fan, 2009b: Impacts of urbanization on a summer heavy rainfall in Beijing. Seventh Int. Conf. on Urban Climate, Yokohama, Japan, ICUC, http://www.ide.titech.ac.jp/ $\sim$ icuc7/extended_abstracts/pdf/293667-1-090515123700-002.pdf.

Mohan, M., and A. Kandya, 2015: Impact of urbanization and landuse/land-cover change on diurnal temperature range: A case study of tropical urban airshed of India using remote sensing data. Sci. Total Environ., 506, 453-465, https://doi.org/10.1016/ j.scitotenv.2014.11.006.

Powers, J. G., and Coauthors, 2017: The Weather Research and Forecasting Model: Overview, system efforts, and future directions. Bull. Amer. Meteor. Soc., 98, 1717-1737, https:// doi.org/10.1175/BAMS-D-15-00308.1.

Salamanca, F., and A. Martilli, 2010: A new Building Energy Model coupled with an Urban Canopy Parameterization for urban climate simulations-Part II. Validation with one dimension off-line simulations. Theor. Appl. Climatol., 99, 345356, https://doi.org/10.1007/s00704-009-0143-8.

- - - - M. Tewari, and F. Chen, 2011: A study of the urban boundary layer using different urban parameterizations and high-resolution urban canopy parameters with WRF. J. Appl. Meteor. Climatol., 50, 1107-1128, https://doi.org/ 10.1175/2010JAMC2538.1.

Shi, J., P. Liang, Q. Wan, J. He, W. Zhou, and L. Cui, 2011: A review of the progress of research on urban climate (in Chinese). J. Trop. Meteor., 27, 942-951.

Shrestha, K. L., A. Kondo, C. Maeda, A. Kaga, and Y. Inoue, 2011: Investigating the contribution of urban canopy model and anthropogenic heat emission to urban heat island effect using WRF Model. Trans. Japan Soc. Refrig. Air Cond. Eng., 26, 45-55.

Shui, T., J. Liu, P. Zhang, S. Liu, and Z. Zhao, 2016: Development of an urban canopy model for the evaluation of urban thermal climate with snow cover in severe cold regions. Build. Environ., 95, 160-170, https://doi.org/10.1016/j.buildenv.2015.09.016.

Stull, R. B., 1990: An Introduction to Boundary Layer Meteorology. Kluwer Academic, $666 \mathrm{pp}$.

United Nations, 2015: World urbanization prospects: The 2014 revision. UN, 32 pp., https://esa.un.org/unpd/wup/Publications/ Files/WUP2014-Highlights.pdf.

Varquez, A. C. G., M. Nakayoshi, and M. Kanda, 2015: The effects of highly detailed urban roughness parameters on a sea-breeze numerical simulation. Bound.-Layer Meteor., 154, 449-469, https://doi.org/10.1007/s10546-014-9985-4.

Wang, X., and Y. Gong, 2010: The impact of an urban dry island on the summer heat wave and sultry weather in Beijing City (in Chinese). Chin. Sci. Bull., 55, 1657-1661, https://doi.org/ 10.1007/s11434-010-3088-5.

, W. Lin, L. Yang, R. Deng, and H. Lin, 2007: A numerical study of influences of urban land-use change on ozone distribution 
over Pearl River Delta region, China. Tellus, 59B, 633-641, https://doi.org/10.1111/j.1600-0889.2007.00271.x.

, F. Chen, Z. Wu, M. Zhang, M. Tewari, A. Guenther, and C. Wiedinmyer, 2009a: Impacts of weather conditions modified by urban expansion on surface ozone over the Pearl River Delta and Yangtze River Delta regions, China. Adv. Atmos. Sci., 26, 962-972, https://doi.org/10.1007/s00376-009-8001-2.

- Z. Wu, and G. Liang, 2009b: WRF/CHEM modeling of impacts of weather conditions modified by urban expansion on secondary organic aerosol formation over Pearl River Delta. Particuology, 7, 384-391, https://doi.org/10.1016/j.partic.2009.04.007.

—, J. Liao, J. Zhang, C. Shen, W. Chen, B. Xia, and T. Wang, 2014: A numerical study of regional climate change induced by urban expansion in the Pearl River Delta. J. Appl. Meteor. Climatol., 53, 346-362, https://doi.org/10.1175/JAMC-D-13-054.1.

Wang, Y., J. Wu, Q. Du, and Y. Gao, 2013: Numerical study of the Chongqing high-density buildings environment by the WRF with the different urban canopy (in Chinese). Acta Meteor. Sin., 71, 1130-1145.

Wang, Z., E. Bou-Zeid, and J. A. Smith, 2013: A coupled energy transport and hydrological model for urban canopies evaluated using a wireless sensor network. Quart. J. Roy. Meteor. Soc., 139, 1643-1657, https://doi.org/10.1002/qj.2032.

Xie, B., J. C. H. Fung, A. Chan, and A. Lau, 2012: Evaluation of nonlocal and local planetary boundary layer schemes in the WRF model. J. Geophys. Res., 117, D12103. https://doi.org/ 1029/2011JD017080.

Xie, M., J. Liao, T. Wang, K. Zhu, B. Zhuang, Y. Han, M. Liang, and S. Li, 2016: Modeling of the anthropogenic heat flux and its effect on regional, meteorology and air quality over the Yangtze River Delta region, China. Atmos. Chem. Phys., 16, 6071-6089, https://doi.org/10.5194/acp-16-6071-2016.
Yang, J., Z. Wang, F. Chen, S. Miao, M. Tewari, J. Voogt, and S. Myint, 2015: Enhancing hydrologic modeling in the coupled Weather Research and Forecasting-urban modeling system. Bound.-Layer Meteor., 155, 87-109, https://doi.org/10.1007/ s10546-014-9991-6.

Zhang, H., and D. P. Roy, 2017: Using the $500 \mathrm{~m}$ MODIS land cover product to derive a consistent continental scale $30 \mathrm{~m}$ Landsat land cover classification. Remote Sens. Environ., 197, 15-34, https://doi.org/10.1016/j.rse.2017.05.024.

Zhang, N., Z. Gao, X. Wang, and Y. Chen, 2010: Modeling the impact of urbanization on the local and regional climate in Yangtze River Delta, China. Theor. Appl. Climatol., 102, 331342, https://doi.org/10.1007/s00704-010-0263-1.

_- X. Wang, Y. Chen, W. Dai, and X. Wang, 2016: Numerical simulations on influence of urban land cover expansion and anthropogenic heat release on urban meteorological environment in Pearl River Delta. Theor. Appl. Climatol., 126, 469-479, https://doi.org/10.1007/s00704-015-1601-0.

Zhang, S., L. Zheng, S. Zheng, Y. Zou, W. Lv, and Y. Huang, 2010: Study on the dry island effect in Xiamen city (in Chinese). J. Anhui Agric. Sci., 38, 11329-11332.

Zhang, W., S. Jin, J. Sun, and Y. Zhang, 2002: Primary research on the relationship between building energy consumption and heat island formation (in Chinese). J. Hebei Inst. Archit. Sci. Technol., 19, 15-17.

Zhou, R., W. Jiang, X. He, and G. Liu, 2008: Study on effects of buildings morphology on urban boundary layer using an urban canopy model (in Chinese). Acta Meteor. Sin., 66, 489-499.

Zhou, X., and H. Chen, 2018: Impact of urbanization-related land use land cover changes and urban morphology changes on the urban heat island phenomenon. Sci. Total Environ., 635, 14671476, https://doi.org/10.1016/j.scitotenv.2018.04.091. 